Cochrane Database of Systematic Reviews

\title{
Clinically-indicated replacement versus routine replacement of peripheral venous catheters (Review)
}

Webster J, Osborne S, Rickard CM, Marsh N

Webster J, Osborne S, Rickard CM, Marsh N.

Clinically-indicated replacement versus routine replacement of peripheral venous catheters.

Cochrane Database of Systematic Reviews 2019, Issue 1. Art. No.: CD007798.

DOI: 10.1002/14651858.CD007798.pub5.

www.cochranelibrary.com 
TABLE OF CONTENTS

HEADER 1

ABSTRACT

PLAIN LANGUAGE SUMMARY ....

SUMMARY OF FINDINGS

BACKGROUND

OBJECTIVES

METHODS

Figure 1.

RESULTS

Figure 2.

Figure 3.

Figure 4.

Figure 5.

Figure 6.

DISCUSSION

AUTHORS' CONCLUSIONS

ACKNOWLEDGEMENTS

REFERENCES

CHARACTERISTICS OF STUDIES

DATA AND ANALYSES

Analysis 1.1. Comparison 1 Clinically-indicated versus routine change, Outcome 1 Catheter-related blood stream infection. ....

Analysis 1.2. Comparison 1 Clinically-indicated versus routine change, Outcome 2 Phlebitis.

Analysis 1.3. Comparison 1 Clinically-indicated versus routine change, Outcome 3 Phlebitis per device days.

Analysis 1.4. Comparison 1 Clinically-indicated versus routine change, Outcome 4 All-cause blood stream infection.

Analysis 1.5. Comparison 1 Clinically-indicated versus routine change, Outcome 5 Cost.

Analysis 1.6. Comparison 1 Clinically-indicated versus routine change, Outcome 6 Infiltration.

Analysis 1.7. Comparison 1 Clinically-indicated versus routine change, Outcome 7 Catheter blockage.

Analysis 1.8. Comparison 1 Clinically-indicated versus routine change, Outcome 8 Local infection.

Analysis 1.9. Comparison 1 Clinically-indicated versus routine change, Outcome 9 Mortality.

Analysis 1.10. Comparison 1 Clinically-indicated versus routine change, Outcome 10 Pain during infusion.

APPENDICES

WHAT'S NEW

HISTORY

CONTRIBUTIONS OF AUTHORS

DECLARATIONS OF INTEREST

SOURCES OF SUPPORT

DIFFERENCES BETWEEN PROTOCOL AND REVIEW

INDEX TERMS 
[Intervention Review]

\section{Clinically-indicated replacement versus routine replacement of peripheral venous catheters}

Joan Webster1,2,3, Sonya Osborne ${ }^{4}$, Claire M Rickard ${ }^{1,5}$, Nicole Marsh ${ }^{1}$

1 National Centre of Research Excellence in Nursing, Centre for Health Practice Innovation, Menzies Health Institute Queensland, Griffith University, Brisbane, Australia. ${ }^{2}$ School of Nursing and Midwifery, The University of Queensland, Brisbane, Australia. ${ }^{3} \mathrm{Nursing}$ and Midwifery Research Centre, Royal Brisbane and Women's Hospital, Herston, Australia. ${ }^{4}$ School of Public Health and Social Work, Institute of Health and Biomedical Innovation, Queensland University of Technology, Brisbane, Australia. ${ }^{5}$ Alliance for Vascular Access Teaching and Research (AVATAR), Menzies Health Institute Queensland, Griffith University, Brisbane, Australia

Contact address: Joan Webster, Nursing and Midwifery Research Centre, Royal Brisbane and Women's Hospital, Butterfield Street, Herston, Queensland, 4029, Australia. joan.webster@health.qld.gov.au, wigan1943@bigpond.com.

Editorial group: Cochrane Vascular Group.

Publication status and date: New search for studies and content updated (no change to conclusions), published in Issue 1, 2019.

Citation: Webster J, Osborne S, Rickard CM, Marsh N. Clinically-indicated replacement versus routine replacement of peripheral venous catheters. Cochrane Database of Systematic Reviews 2019, Issue 1. Art. No.: CD007798. DOI: 10.1002/14651858.CD007798.pub5.

Copyright ( 2019 The Cochrane Collaboration. Published by John Wiley \& Sons, Ltd.

\section{A B S T R A C T}

\section{Background}

US Centers for Disease Control guidelines recommend replacement of peripheral intravenous catheters (PIVC) no more frequently than every 72 to 96 hours. Routine replacement is thought to reduce the risk of phlebitis and bloodstream infection. Catheter insertion is an unpleasant experience for patients and replacement may be unnecessary if the catheter remains functional and there are no signs of inflammation or infection. Costs associated with routine replacement may be considerable. This is the third update of a review first published in 2010 .

\section{Objectives}

To assess the effects of removing peripheral intravenous catheters when clinically indicated compared with removing and re-siting the catheter routinely.

\section{Search methods}

The Cochrane Vascular Information Specialist searched the Cochrane Vascular Specialised Register, CENTRAL, MEDLINE, Embase and CINAHL and World Health Organization International Clinical Trials Registry Platform and ClinicalTrials.gov trials registers to 18 April 2018. We also undertook reference checking, and contacted researchers and manufacturers to identify additional studies.

\section{Selection criteria}

We included randomised controlled trials that compared routine removal of PIVC with removal only when clinically indicated, in hospitalised or community-dwelling patients receiving continuous or intermittent infusions.

\section{Data collection and analysis}

Three review authors independently reviewed trials for inclusion, extracted data, and assessed risk of bias using Cochrane methods. We used GRADE to assess the overall evidence certainty.

\section{Main results}

This update contains two new trials, taking the total to nine included studies with 7412 participants. Eight trials were conducted in acute hospitals and one in a community setting. We rated the overall certainty of evidence as moderate for most outcomes, due to serious risk 
of bias for unblinded outcome assessment or imprecision, or both. Because outcome assessment was unblinded in all of the trials, none met our criteria for high methodological quality.

\section{Primary outcomes}

Seven trials (7323 participants), assessed catheter-related bloodstream infection (CRBSI). There is no clear difference in the incidence of CRBSI between the clinically indicated (1/3590) and routine change (2/3733) groups (risk ratio (RR) $0.61,95 \%$ confidence interval (Cl) 0.08 to 4.68), low-certainty evidence (downgraded twice for serious imprecision).

All trials reported incidence of thrombophlebitis and we combined the results from seven of these in the analysis (7323 participants). We excluded two studies in the meta-analysis because they contributed to high heterogeneity. There is no clear difference in the incidence of thrombophlebitis whether catheters were changed according to clinical indication or routinely (RR $1.07,95 \% \mathrm{Cl} 0.93$ to 1.25 ; clinically indicated 317/3590; 3-day change 307/3733, moderate-certainty evidence, downgraded once for serious risk of bias). The result was unaffected by whether the infusion was continuous or intermittent. Six trials provided thrombophlebitis rates by number of device days (32,709 device days). There is no clear difference between groups (RR 0.90, 95\% Cl 0.76 to 1.08 ; clinically indicated 248/17,251; 3-day change 236/15,458; moderate-certainty evidence, downgraded once for serious risk of bias).

One trial (3283 participants), assessed all-cause blood stream infection (BSI). We found no clear difference in the all-cause BSI rate between the two groups (RR $0.47,95 \% \mathrm{Cl} 0.15$ to 1.53 ; clinically indicated: $4 / 1593$ (0.02\%); routine change $9 / 1690$ (0.05\%); moderate-certainty evidence, downgraded one level for serious imprecision).

Three trials (4244 participants), investigated costs; clinically indicated removal probably reduces device-related costs by approximately AUD 7.00 compared with routine removal (MD $-6.96,95 \% \mathrm{Cl}-9.05$ to -4.86 ; moderate-certainty evidence, downgraded once for serious risk of bias).

\section{Secondary outcomes}

Six trials assessed infiltration (7123 participants). Routine replacement probably reduces infiltration of fluid into surrounding tissues compared with a clinically indicated change (RR 1.16 (95\% Cl 1.06 to 1.26 ; routine replacement $747 / 3638$ (20.5\%); clinically indicated $834 / 3485$ (23.9\%); moderate-certainty evidence, downgraded once for serious risk of bias).

Meta-analysis of seven trials (7323 participants), found that rates of catheter failure due to blockage were probably lower in the routinereplacement group compared to the clinically indicated group (RR 1.14, 95\% Cl 1.01 to 1.29; routine-replacement 519/3733 (13.9\%); clinically indicated 560/3590 (15.6\%); moderate-certainty evidence, downgraded once for serious risk of bias).

Four studies (4606 participants), reported local infection rates. It is uncertain if there are differences between groups (RR 4.96, $95 \% \mathrm{Cl} 0.24$ to 102.98 ; clinically indicated 2/2260 (0.09\%); routine replacement 0/2346 (0.0\%); very low-certainty evidence, downgraded one level for serious risk of bias and two levels for very serious imprecision).

One trial (3283 participants), found no clear difference in the incidence of mortality when clinically indicated removal was compared with routine removal (RR 1.06, $95 \% \mathrm{Cl} 0.27$ to 4.23 ; low-certainty evidence, downgraded two levels for very serious imprecision).

One small trial (198 participants) reported no clear difference in device-related pain between clinically indicated and routine removal groups (MD $-0.60,95 \% \mathrm{Cl}-1.44$ to 0.24 ; low-certainty evidence, downgraded one level for serious risk of bias and one level for serious imprecision).

The pre-planned outcomes 'number of catheter re-sites per patient', and 'satisfaction' were not reported by any studies included in this review.

\section{Authors' conclusions}

There is moderate-certainty evidence of no clear difference in rates of CRBSI, thrombophlebitis, all-cause BSI, mortality and pain between clinically indicated or routine replacement of PIVC. We are uncertain if local infection is reduced or increased when catheters are changed when clinically indicated. There is moderate-certainty evidence that infiltration and catheter blockage is probably lower when PIVC are changed routinely; and moderate-certainty evidence that clinically indicated removal probably reduces device-related costs. The addition of two new trials for this update found no further evidence to support changing catheters every 72 to 96 hours. Healthcare organisations may consider changing to a policy whereby catheters are changed only if there is a clinical indication to do so, for example, if there were signs of infection, blockage or infiltration. This would provide significant cost savings, spare patients the unnecessary pain of routine resites in the absence of clinical indications and would reduce time spent by busy clinicians on this intervention. To minimise PIVC-related complications, staff should inspect the insertion site at each shift change and remove the catheter if signs of inflammation, infiltration, occlusion, infection or blockage are present, or if the catheter is no longer needed for therapy.

\section{PLAIN LANGUAGE SUMMARY}

\section{Replacing a peripheral venous catheter when clinically indicated versus routine replacement}




\section{Review question}

We reviewed the evidence about the effects of changing a catheter routinely (every three to four days) or changing the catheter only if there were signs or symptoms of a problem with the catheter remaining in place.

\section{Background}

Most hospital patients receive fluids or medications via a peripheral intravenous catheter at some time during their hospital stay. An intravenous catheter (also called an IV drip, an IV line or intravenous cannula) is a short, hollow tube placed in the vein to allow administration of medications, fluids or nutrients directly into the bloodstream. These catheters are often replaced every three to four days to try to prevent irritation of the vein or infection of the blood. However, replacing the catheter may cause discomfort to patients and is quite costly. This is the third update of a review first published in 2010.

\section{Study characteristics}

In April 2018 we searched for randomised controlled trials (RCTs) that compared changing catheters every 72 to 96 hours (routine change) with changing the catheter only if there were complications or therapy was complete. We measured catheter-related blood stream infection, phlebitis and other problems associated with peripheral catheters, such as local infection and catheter blockage. We included two new studies for this update, bringing the total to nine studies with 7412 participants.

\section{Key results}

We found no clear difference in rates of catheter-related blood stream infection, phlebitis (inflammation of the vein), blood stream infection from any cause, local infection, mortality or pain. We are uncertain if local infection is reduced or increased when catheters are changed when clinically indicated. Infiltration (fluid seeping into the tissue around the catheter) and catheter blockage (an inability to infuse fluids or medication through the catheter), are probably reduced when catheters are changed routinely. Cost is reduced when catheters are replaced when there was a clinical indication to do so. The pre-planned outcomes 'number of catheter re-sites per patient', and 'satisfaction' were not reported by any studies included in the review.

\section{Quality of the evidence}

The overall quality of the evidence was judged to be moderate for most outcomes, which leaves us uncertain of our findings. The uncertainty is largely due to outcomes, such as phlebitis, being assessed by people who were aware of the group allocation, which may or may not affect their decision about whether a problem is present or absent. 
SUMMARY OF FINDINGS

Summary of findings for the main comparison. Effects of clinically-indicated replacement compared to routine change of peripheral intravenous catheters

Effects of clinically indicated replacement compared to routine change of peripheral intravenous catheters (PIVC)

Patient or population: any patient requiring a PIVC expected to remain in-situ for at least 3 days

Setting: hospital or community

Intervention: PIVC replaced if a clinical indication is present

Comparison: changing the PIVC routinely, according to a set time frame (usually between 72-96 hours)

\begin{tabular}{|c|c|c|c|c|c|c|}
\hline \multirow[t]{2}{*}{ Outcomes } & \multicolumn{2}{|c|}{$\begin{array}{l}\text { Anticipated absolute effects }{ }^{*} \\
(95 \% \mathrm{CI})\end{array}$} & \multirow[t]{2}{*}{$\begin{array}{l}\text { Relative effect } \\
(95 \% \mathrm{Cl})\end{array}$} & \multirow{2}{*}{$\begin{array}{l}\text { № of partici- } \\
\text { pants } \\
\text { (studies) }\end{array}$} & \multirow{2}{*}{$\begin{array}{l}\text { Certainty of } \\
\text { the evidence } \\
\text { (GRADE) }\end{array}$} & \multirow[t]{2}{*}{ Comments } \\
\hline & $\begin{array}{l}\text { Risk with ro } \\
\text { tine change }\end{array}$ & $\begin{array}{l}\text { Risk with clini- } \\
\text { cally indicated }\end{array}$ & & & & \\
\hline \multirow{2}{*}{$\begin{array}{l}\text { Catheter-re- } \\
\text { lated blood } \\
\text { stream infec- } \\
\text { tion } \\
\text { (during hospi- } \\
\text { talisation) }\end{array}$} & \multicolumn{2}{|c|}{ Study population } & \multirow{2}{*}{$\begin{array}{l}\text { RR } 0.61 \\
\text { (0.08 to } 4.68)\end{array}$} & \multirow{2}{*}{$\begin{array}{l}7323 \\
\text { (7 RCTs) }\end{array}$} & \multirow{2}{*}{$\begin{array}{l}\oplus \oplus \ominus \ominus \\
\text { Low }^{1}\end{array}$} & \multirow{2}{*}{$\begin{array}{l}\text { There is no clear difference in the incidence of catheter- } \\
\text { related blood stream infection. The wide } \mathrm{Cl} \text { includes the } \\
\text { possibility of both increased and decreased infection. } \\
\text { The true effect could range from a } 92 \% \text { reduction to a } \\
4.68 \text { times increase in the clinically indicated group. }\end{array}$} \\
\hline & 1 per 1000 & $\begin{array}{l}0 \text { per } 1000 \\
(0 \text { to } 3)\end{array}$ & & & & \\
\hline \multirow{2}{*}{$\begin{array}{l}\text { Throm- } \\
\text { bophlebitis } \\
\text { (during hospi- } \\
\text { talisation) }\end{array}$} & \multicolumn{2}{|c|}{ Study population } & \multirow{2}{*}{$\begin{array}{l}\text { RR } 1.07 \\
\text { (0.93 to } 1.25 \text { ) }\end{array}$} & \multirow{2}{*}{$\begin{array}{l}7323 \\
\text { (7 RCTs) }\end{array}$} & \multirow{2}{*}{$\begin{array}{l}\oplus \oplus \oplus \ominus \\
\text { Moderate } 2\end{array}$} & \multirow{2}{*}{$\begin{array}{l}\text { There is no clear difference in the incidence of phlebitis } \\
\text { between the clinically indicated and routine-change } \\
\text { groups. Although the outcome assessment for laborato- } \\
\text { ry-based outcomes, such as blood stream infection was } \\
\text { blinded; only } 2 \text { trials reported these outcomes. Most } \\
\text { outcomes were assessed by clinicians or researchers } \\
\text { who were aware of the group to which the participant } \\
\text { belonged. }\end{array}$} \\
\hline & 82 per 1000 & $\begin{array}{l}88 \text { per } 1000 \\
(76 \text { to } 103)\end{array}$ & & & & \\
\hline \multirow{3}{*}{$\begin{array}{l}\text { Throm- } \\
\text { bophlebitis } \\
\text { (per device } \\
\text { days) } \\
\text { (during hospi- } \\
\text { talisation) }\end{array}$} & \multicolumn{2}{|c|}{ Study population } & \multirow{2}{*}{$\begin{array}{l}\text { RR } 0.90 \\
\text { (0.76 to } 1.08 \text { ) }\end{array}$} & \multirow{2}{*}{$\begin{array}{l}32,709 \text { device } \\
\text { days } \\
\text { (6 RCTs) }\end{array}$} & \multirow{2}{*}{$\begin{array}{l}\oplus \oplus \oplus \ominus \\
\text { Moderate }^{2}\end{array}$} & \multirow{2}{*}{$\begin{array}{l}\text { There is no clear difference in the incidence of phlebitis } \\
\text { when assessed correctly (incidence/ } 1000 \text { device days) } \\
\text { between the clinically indicated and routine-change } \\
\text { groups. The true effect could range from a } 24 \% \text { reduc- } \\
\text { tion to an } 8 \% \text { increase in the clinically indicated group. }\end{array}$} \\
\hline & 15 per 1000 & $\begin{array}{l}14 \text { per } 1000 \\
(12 \text { to } 16)\end{array}$ & & & & \\
\hline & \multicolumn{2}{|c|}{ Study population } & $\begin{array}{l}\text { RR } 0.47 \\
\text { (0.15 to } 1.53 \text { ) }\end{array}$ & $\begin{array}{l}3283 \\
(1 \mathrm{RCT})\end{array}$ & $\begin{array}{l}\oplus \oplus \oplus \ominus \\
\text { Moderate }\end{array}$ & \\
\hline
\end{tabular}




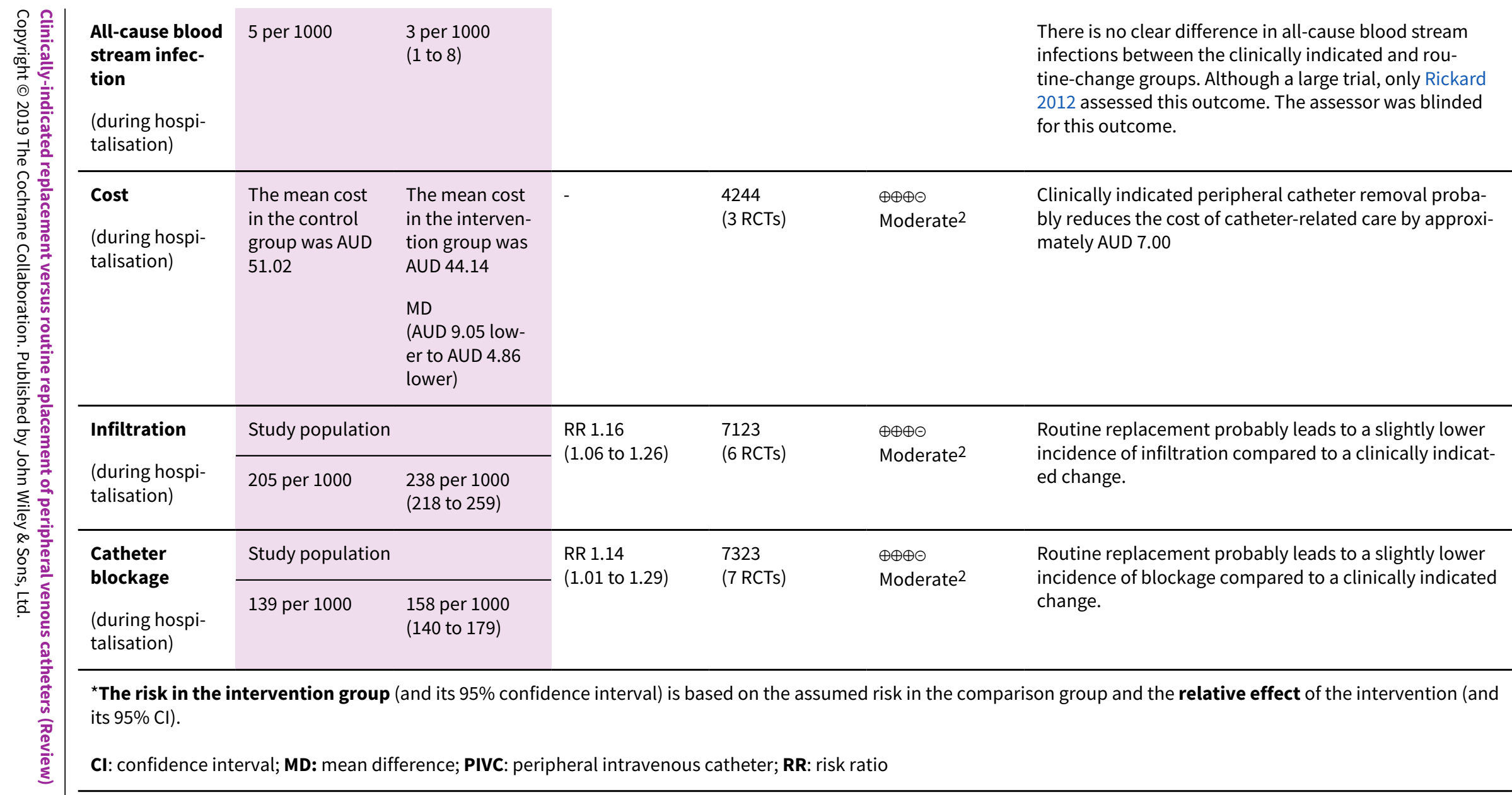

\section{GRADE Working Group grades of evidence}

High certainty: we are very confident that the true effect lies close to that of the estimate of the effect.

Moderate certainty: we are moderately confident in the effect estimate: the true effect is likely to be close to the estimate of the effect, but there is a possibility that it is substantially different.

Low certainty: our confidence in the effect estimate is limited: the true effect may be substantially different from the estimate of the effect.

Very low certainty: we have very little confidence in the effect estimate: the true effect is likely to be substantially different from the estimate of effect.

${ }^{1}$ Downgraded two levels for very serious inconsistency.

2 Downgraded one level for serious risk of bias (no blind outcome assessment).

3 Downgraded one level for serious inconsistency. 


\section{B A C K G R O U N D}

Among hospitalised patients, vascular access is the most common invasive procedure with $80 \%$ of hospital admissions involving an average of two vascular access devices per patient (Hadaway 2012). Peripheral intravenous (IV) access is associated with a pooled proportion for phlebitis of 36\% (Marsh 2018a), and a pooled proportion catheter-related blood stream infection (CRBSI) rate of less than $0.1 \%$ (Marsh 2018a). A number of current guidelines have been updated to reflect findings from previous versions of this systematic review (Webster 2015), recommending changing short peripheral intravenous catheters (PIVC) when there is a clinical indication to do so (Infusion Nurses Society 2011; Loveday 2014). However, the influential Centers for Disease Control (CDC) guidelines state that, "no recommendation is made regarding replacement of peripheral catheters in adults only when clinically indicated" (p. 15, O'Grady 2011). In practice most hospitals already exempt patients with poor veins from routine changes and, for children, CDC guidelines have always recommended that PIVC be replaced only when clinically indicated (O'Grady 2011). In recent years, there have been improvements in catheter design and composition, and more recent studies, including an earlier version of this review (Webster 2015), indicate that the recommendation may need to be revised. Based on level 1 evidence, the most recent Infusion Nursing Standards of Practice in the USA and the epic3 National Evidence Based Guidelines in the UK recommend that short PIVC should be replaced when clinically indicated, unless the patient is receiving parenteral nutrition peripherally (Infusion Nurses Society 2011; Loveday 2014). The projected fiveyear savings from implementing clinically indicated PIVC removal policies is USD 300 million and 1 million health-worker hours in the USA alone (Tuffaha 2014a; Tuffaha 2014b).

\section{Description of the condition}

Catheter-related blood stream infection (CRBSI), defined as the presence of bacteraemia originating from an intravenous (IV) catheter, is a rare but severe outcome of IV catheterisation (Gahlot 2014). The infection occurs when bacteria track along the catheter and enter the bloodstream. The bacterial source may be the patient's own skin or that of a healthcare provider; CRBSI has an attributable mortality rate of $12 \%$ to $25 \%$ (Maki 2006). Peripheral vein infusion thrombophlebitis (phlebitis) is characterised by pain, erythema (redness of the skin), swelling, and palpable thrombosis of the cannulated vein (Monreal 1999). Diagnosis remains controversial and a number of grading systems have been proposed, although with limited validation testing performed (Ray-Barruel 2014). These include the Maddox scale (Maddox 1977), and the Baxter scale (Panadero 2002), which rank infusion thrombophlebitis according to the severity of clinical signs and symptoms. The scales are limited because not all symptoms may be present, or they may not always be present in the clusters described in the scales. Consequently, many investigators define peripheral vein infusion thrombophlebitis based on two or more of the following; pain, tenderness, warmth, erythema, swelling, and a palpable cord (Maki 1991; Monreal 1999). More recently, a new definition for phlebitis has been proposed, one based on a more objective assessment of the insertion site (Rickard 2012). Although the precise pathogenesis of thrombus formation remains unclear, it is thought to be related to inflammation of the vein wall. Studies have been unable to demonstrate a high correlation between phlebitis and catheter infection and Maki has suggested that phlebitis may primarily be a physical response (Maki 1991). This suggestion was supported by Catney and colleagues when investigating the aetiology of phlebitis; they found that drug irritation, size of catheter, and the person inserting the catheter were all predictors of phlebitis (Catney 2001). Utrasonographic imaging has demonstrated thrombus formation in two-thirds of catheterised veins studied and it has been suggested that catheter design may be implicated (Everitt 1997). Thus, possible causes of phlebitis are mechanical irritation from the catheter and the properties of the infusate or IV-administered medications, particularly flucloxacillin, which is associated with a two-fold increase in phlebitis (Marsh 2018b).

\section{Description of the intervention}

The intervention under consideration is replacing an PIVC only if there are clinical indications to do so. Clinical indications include blockage, pain, redness, infiltration, swelling, leakage, and phlebitis, as well as when therapy is completed.

\section{How the intervention might work}

Each time a catheter is inserted, the patient's skin integrity is breached and a potential portal for pathogens is provided. For example, a significant relationship was found between the number of times PIVC were inserted and phlebitis in a study of 568 IV sites (Uslusoy 2008). Consequently, it may be prudent to limit the frequency of PIVC replacements if there is no clinical reason to do so. There is some support for this approach from observational studies that have compared outcomes between catheters remaining in situ for varying periods. In an adequately powered observational study, which included participants from medical wards and intensive care units, the investigators were unable to demonstrate any increased risk of phlebitis beyond the second day (Bregenzer 1998). Similarly, in a retrospective study of 784 IV catheter starts, the rate of phlebitis on days one and two was $11.5 \%$, dropping to $3.9 \%$ by day four (Homer 1998). The authors concluded that, "there appeared to be less risk in continuing therapy beyond the third day than re-starting the therapy" (pp 304). Catney 2001 also failed to demonstrate any increase in phlebitis rates with the passage of time, with failure rates being less at 144 hours (1.9\%) than at 72 hours (2.5\%) (Catney 2001). Similarly, in a prospective investigation of 305 PIVC there were 10 cases of infusion phlebitis amongst patients who had their catheter in situ for fewer than 72 hours whereas none were reported in patients where the dwell time was longer (White 2001). In the same study, there were three cases of post-infusion phlebitis; these all occurred amongst participants whose PIVC had been in place for fewer than 72 hours. Even among a high-risk population of oncology and infectious diseases patients, phlebitis rates were no different when length of cannulation was dichotomised to three days or fewer and more than three days (Cornely 2002).

\section{Why it is important to do this review}

These observational studies and previous versions of our Cochrane Review (Webster 2010; Webster 2013; Webster 2015), create uncertainty around the US Centers for Disease Control (CDC) guidelines relating to PIVC management, which states that clinically indicated replacement in adults is an "unresolved issue" (O'Grady 2011). The recommendation referenced an earlier version of this review (Webster 2010), which showed 'no difference' between the two approaches to PIVC replacement. As long as 
discrepancies exist between the CDC recommendations, often seen as the gold standard, and other international guidelines, updating this review with contemporary evidence is important. Particularly when 'choosing wisely' commentators find that "routine replacement should be considered a thing that we do for no reason" (Patel 2017). The review is also important because insertion of a PIVC may be painful, especially when placed in the hand or wrist, with an average score of 4.5 on a 10-point pain scale (Tan 2016), so preventing unnecessary replacements may reduce a potentially traumatic experience for patients. Additionally, routine replacement has significant cost implications for the facility. Routine replacement costs approximately AUD 7 more per patient compared with clinically indicated replacement (Tuffaha 2014a). With an estimated two billion PIVC used globally each year (Rickard 2018), there is a clear need to provide direction for clinicians and administrators by systematically searching for and appraising relevant studies to add to the review.

\section{OB JECTIVES}

To assess the effects of removing peripheral intravenous catheters when clinically indicated compared with removing and re-siting the catheters routinely.

\section{METHODS}

\section{Criteria for considering studies for this review}

\section{Types of studies}

We considered all randomised controlled trials (RCTs) comparing routine removal of PIVC with removal only when clinically indicated. Cross-over trials were not eligible for inclusion.

\section{Types of participants}

We included any patient requiring a PIVC to be in situ for at least three days for the administration of intermittent or continuous therapy (this may include patients in hospitals, nursing homes, or in community settings). We excluded participants receiving parenteral fluids.

\section{Types of interventions}

We included short PIVC made from any type of material (for example metal, plastic); non-coated or coated with any type of product (for example antibiotic, anticoagulant); or covered by any type of dressing (for example gauze, clear, occlusive). We included any duration of time before routine replacement versus clinically indicated replacement. We excluded midline catheters and long peripheral catheters.

\section{Types of outcome measures}

\section{Primary outcomes}

- Catheter-related blood stream infection (CRBSI, defined as a positive blood culture from a peripheral vein; clinical signs of infection; no other apparent source for the bloodstream infection except the IV catheter; and colonised IV catheter tip culture with the same organism as identified in the blood)

- Thrombophlebitis (using any definition identified by the trial author)
- All-cause bloodstream infection (BSI, defined as a any positive blood culture drawn from a peripheral vein while an IV catheter is in situ or for 48 hours after removal)

- Cost (in terms of materials and labour associated with IV catheter-related insertion)

\section{Secondary outcomes}

- Infiltration (defined as permeation of IV fluid into the interstitial compartment, causing swelling of the tissue around the site of the catheter)

- Catheter occlusion or blockage (identified by the inability to infuse fluids)

- Number of catheter re-sites per participant

- Local infection (using any definition identified by the trial author)

- Mortality

- Pain during infusion (measured by any validated pain assessment scale)

- Satisfaction (measured by any validated satisfaction scale)

\section{Search methods for identification of studies}

There was no restriction on language. If foreign language studies had been found, we intended to seek initial translation of abstracts for the application of the inclusion and exclusion criteria. Where necessary, the methods, results, and discussion sections would have been translated for inclusion in the review.

\section{Electronic searches}

The Cochrane Vascular Information Specialist (CIS) conducted systematic searches of the following databases for RCTs without language, publication year or publication status restrictions:

- the Cochrane Vascular Specialised Register via the Cochrane Register of Studies (CRS-Web searched on 18 April 2018);

- the Cochrane Central Register of Controlled Trials (CENTRAL; 2018, Issue 3) via Cochrane Register of Studies Online;

- MEDLINE (Ovid MEDLINE ${ }^{\circledR}$ Epub Ahead of Print, In-Process \& Other Non-Indexed Citations, Ovid MEDLINE ${ }^{\circledR}$ Daily and Ovid MEDLINE ${ }^{\circledR}$ ) (searched from 1 January 2017 to 18 April 2018);

- Embase Ovid (searched from 1 January 2017 to 18 April 2018);

- CINAHL Ebsco (searched from 1 January 2017 to 18 April 2018);

- AMED Ovid (searched from 1 January 2017 to 18 April 2018).

The Information Specialist modelled search strategies for other databases on the search strategy designed for CENTRAL. Where appropriate, they were combined with adaptations of the highly sensitive search strategy designed by the Cochrane Collaboration for identifying RCTs and controlled clinical trials (as described in the Cochrane Handbook for Systematic Reviews of Interventions Chapter 6, Lefebvre 2011). Search strategies for major databases are provided in Appendix 1.

The Information Specialist searched the following trials registries on 18 April 2018:

- the World Health Organization International Clinical Trials Registry Platform (apps.who.int/trialsearch);

- ClinicalTrials.gov (clinicaltrials.gov/). 


\section{Searching other resources}

We contacted researchers and manufacturers in order to obtain any unpublished data. Reference lists of potentially useful articles were also searched.

We also searched the following clinical trials registries:

- ClinicalTrials.gov (clinicaltrials.gov/; 12 July 2018), using the terms peripheral and intravenous and catheter and routine;

- World Health Organization International Clinical Trials Registry Platform (ICTRP; apps.who.int/trialsearch/) (12 July 2018) using the terms peripheral and intravenous and catheter;

- Australian and New Zealand Clinical Trials Registry (ANZCTR; 12 July 2018), using the terms peripheral and intravenous and catheter.

\section{Data collection and analysis}

\section{Selection of studies}

Two review authors independently reviewed titles and abstracts identified through the search process (JW, NM). We retrieved full reports of all potentially relevant trials for further assessment of eligibility based on the inclusion criteria. If we excluded any full texts, we recorded the reasons. We completed a PRISMA flow chart (Liberati 2009; Figure 1), to summarise the selection process. As the review authors were also the investigators on some of the included trials, we allocated assessment to a review author who was not an investigator (former author $\mathrm{KN}$ ). We settled differences of opinion by consensus or referral to a third review author. There was no blinding of authorship. 


\section{Figure 1. Study flow diagram}

7 studies included in previous
version of the review

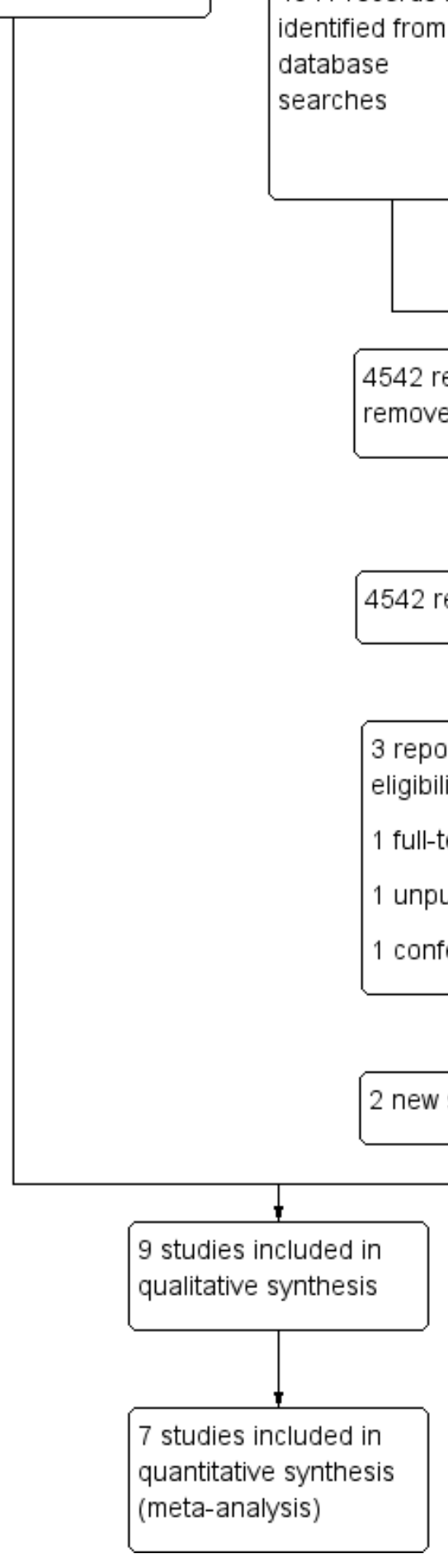

\section{Data extraction and management}

Following Cochrane Vascular recommendations, two review authors (two of JW, CR, or SO) independently extracted data to a pre-tested data extraction form. We resolved disagreements by discussion and, where necessary, by a involving third review author.

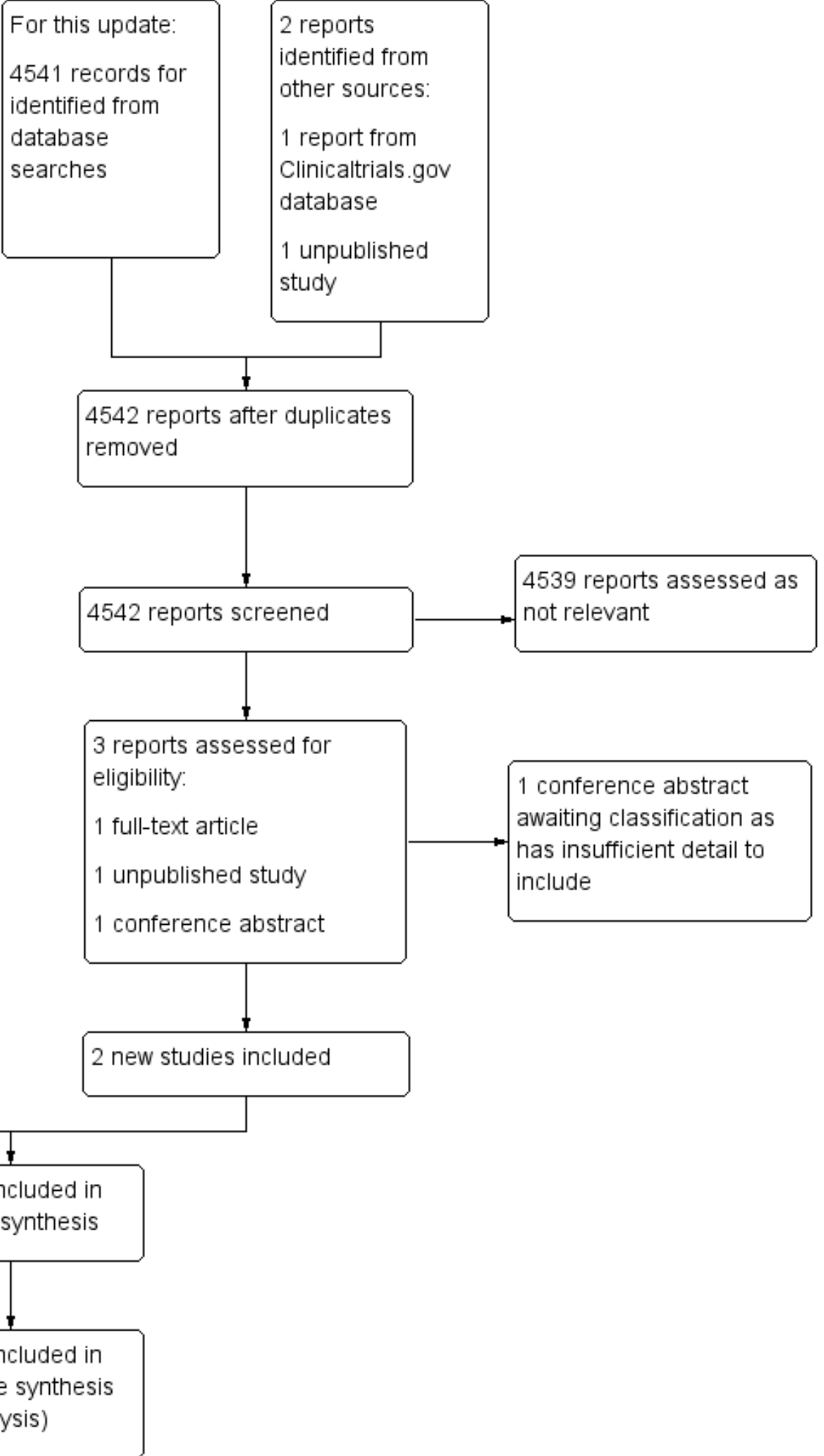

We contacted authors of published and unpublished trials for additional information.

We extracted the following main sets of data from each included study: 
- lead author, date;

- study participant inclusion criteria;

- country where the research was conducted;

- participants' gender and age;

- study design, randomisation processes, allocation concealment;

- intervention descriptions;

- intervention setting (hospital, home, residential aged care facilities);

- numbers of participants in each trial arm, withdrawals and dropouts;

- outcome measures, time(s) at which outcomes were assessed;

- funding source;

- ethics approval and consent;

- prospective registration on a clinical trials registry.

The first review author (JW) entered the data into Review Manager 5 , with another review author (NM) checking data entry accuracy (Review Manager 2014).

\section{Assessment of risk of bias in included studies}

Two review authors (two of JW, CR, SO, NM) independently assessed the included studies using the Cochrane Collaboration tool for assessing risk of bias (Higgins 2017). This tool addresses six specific domains, namely sequence generation, allocation concealment, blinding, incomplete outcome data, selective outcome reporting, and other issues (for example extreme baseline imbalance). We resolved any disagreements between review authors by consensus or referral to a third review author. We contacted the investigators of included trials to resolve any ambiguities.

\section{Measures of treatment effect}

For individual trials, effect measures for categorical outcomes included risk ratio (RR) with its 95\% confidence interval $(\mathrm{Cl})$. For statistically significant effects, we calculated the number needed to treat for an additional beneficial outcome (NNTB) or number needed to treat for an additional harmful outcome (NNTH). For continuous outcomes the effect measure we used was mean difference (MD) or, if the scale of measurement differed across trials, standardised mean difference (SMD), each with its $95 \% \mathrm{Cl}$. For any meta-analyses (see below), for categorical outcomes we calculated the typical estimates of RR with their $95 \% \mathrm{Cl}$; and for continuous outcomes we calculated the mean difference (MD) or a summary estimate for standardised mean difference (SMD), each with its $95 \%$ $\mathrm{Cl}$. We analysed data using the Cochrane Collaboration's Review Manager 5 software (Review Manager 2014).

\section{'Summary of findings' tables}

To assess the overall body of evidence, we developed 'Summary of findings' tables for the following outcomes, using GRADE approach.

- CRBSI

- Thrombophlebitis

- Thrombophlebitis per device days

- All-cause BSI

- Cost

- Infiltration

\section{- Catheter blockage}

We assessed the certainty of the body of evidence against five principle domains: 1) limitations in design and implementation; 2) indirectness of evidence or generalisability of findings; 3 ) inconsistency of results, for example unexplained heterogeneity and inconsistent findings; 4) imprecision of results where confidence intervals were wide; and 5) other potential biases, for example publication bias or high manufacturer involvement (Schünemann 2017). We downgraded the evidence from 'high certainty' by one level for serious risk of bias or by two for very serious risk of bias.

\section{Unit of analysis issues}

Unit of analysis issues may arise in catheter trials when the participant is randomised but the number of outcomes are reported per catheter. We resolved this issue by using the participant as the unit of analysis if the number of catheters and number of participants were similar (assuming one catheter per individual). The more difficult challenge is where studies randomise at the participant level, use the allocated intervention on multiple catheters per participant, and then analyse outcomes per catheter. Such approaches should be treated as cluster trials. If a cluster trial had been correctly analysed, we planned to include effect estimates in any meta-analysis using the generic inverse methods in Review Manager 5 (Review Manager 2014).

Comparing longer and shorter PIVC dwell times on crude incidence of complications is also problematic; this does not take into account the cumulative daily risk inherent with peripheral intravenous device (IVD) use. There is clearly a 'per day risk' that is present, and grows with each day of intravascular treatment, regardless of how many IVDs are used over the period of therapy. This cannot be extrapolated to mean that restricting (removing) individual IVDs will reduce overall risk. That is, an IVD in situ for seven days has seven days of exposure to risk compared with an IVD in use for only three days, but if the patient requires therapy for seven days in total then using multiple catheters over the period may not reduce risk but merely divide the same risk between multiple catheters. Appropriate time comparisons need to be made using statistics such as Kaplan-Meier analysis, logistic regression, or Cox proportional models. It is vital that the participant is used as the unit of measurement (denominator for comparison), not the IVD. If a patient requires therapy, for example for five days, they may have one catheter used for the entire time or alternately multiple IVDs used over the five days. If the multiple catheters are viewed independently they may appear to have lower risk per catheter but the total risk for the patient over the five days may be the same. We dealt with this by only including studies where data were available per participant rather than per catheter. Where data were not originally analysed in this format we contacted the investigators (for example Van Donk 2009), to get these data. For comparison, we also included an analysis of phlebitis per catheter days where this information was available.

Where a cluster-randomised trial had been included but incorrectly analysed, we planned to record the unit of analysis issue in our 'Risk of Bias' assessment. If possible, we planned to approximate the correct analyses based on guidance from the Cochrane Handbook for Systematic Reviews of Interventions (Higgins 2011a). That is, we calculated the 'design effect' by using the formula 1+ (M-1) ICC where $M$ is the average size of each cluster, We did identify one 
cluster-randomised trial, the results of which did not appear to have been adjusted (Xu 2017). For this trial, we were unable to identify an external intracluster correlation coefficient (ICC), so used an estimate of 0.02 and calculated the average cluster size to be 58.9.

\section{Dealing with missing data}

If any outcome data remained missing despite our attempts to obtain complete outcome data from trial authors, we assessed the risk of bias of the missing data and decided if the missing data were at 'low' or 'high' risk of bias according to our 'Risk of bias' criteria (Higgins 2017). If we considered data to be missing at random, we analysed the available information. If standard deviations were missing, we planned to impute them from other studies or, where possible, compute them from standard errors using the formula SD $=\mathrm{SEX} \sqrt{ }^{-} \mathrm{N}$ where these were available (Higgins 2011b).

\section{Assessment of heterogeneity}

We explored clinical heterogeneity by examining potentially influential factors, for example, intervention dwell time, care setting, or participant characteristics. We assessed statistical heterogeneity using the $\mathrm{Chi} 2$ test (considering $\mathrm{P}<0.10$ to represent significant heterogeneity), along with the $\mathrm{I}^{2}$ statistic (Higgins 2003), which examines the percentage of total variation across studies due to heterogeneity rather than to chance. We planned to explore potential causes of moderate to significant heterogeneity (12>30\%) and use a random-effects approach to the analyses (Deeks 2017).

\section{Assessment of reporting biases}

We assessed reporting bias using guidelines in the Cochrane Handbook for Systematic Reviews of Interventions (Sterne 2017). Reporting bias occurs when reports of research results are affected by the type and direction of results. We assessed reporting bias in each study as part of our 'Risk of Bias' evaluation. If sufficient study data had been available for individual outcomes (> 10 trials), we would have developed funnel plots and inspected them for evidence of publication bias.

\section{Data synthesis}

Where clinical and statistical heterogeneity was low, we pooled results of comparable trials using a fixed-effect model, and reported the pooled estimate together with its $95 \% \mathrm{Cl}$. Otherwise, we used a random-effects model for our meta-analytic approach. In cases where clinical heterogeneity between studies was similar but heterogeneity was high, we planned to meta-analyse results and attempt to provide an explanation for the heterogeneity. We conducted a narrative review of eligible studies where statistical synthesis of data from more than one study was not possible or considered not appropriate.

\section{Subgroup analysis and investigation of heterogeneity}

We planned to analyse potential sources of heterogeneity using the following subgroup analyses.

- Type of randomisation (truly randomised versus not reported)

- Concealment of allocation (adequate versus not reported)

- Blinding (participants and clinicians blinded versus open-label)

- Statement of withdrawals and losses to follow-up in each group (stated versus not stated)

- Intermittent versus continuous infusion

\section{Sensitivity analysis}

We planned to perform sensitivity analyses to explore the effect of the following criteria:

- Concealment of allocation

- Size of studies (< 100 participants versus at least 100 participants)

- Duration of follow-up

- Unpublished studies

\section{RES U L T S}

\section{Description of studies}

\section{Results of the search}

See Figure 1.

For this update, we identified 4541 unique records through our electronic search. After reading titles and abstracts there were two additional citations which we considered potentially relevant (Chin 2018; Xu 2017). Chin 2018 was an abstract of an Australian trial in newborn infants with insufficient information in the report to consider inclusion. We contacted the author, asking for further study details but have had no response; we have placed a reference to the report in the Studies awaiting classification section of the review. We retrieved the full text of the second study and have included it in this update (Xu 2017). We have also included results from an unpublished study, which we were aware of through our network of intravascular device researchers (Vendramim 2018). We did not find any additional trials in our search of trials registries.

\section{Included studies}

Nine RCTs, involving a total of 7392 participants met the inclusion criteria (Barker 2004; Nishanth 2009; Rickard 2010; Rickard 2012; Van Donk 2009; Vendramim 2018; Webster 2007; Webster 2008; Xu 2017), see Characteristics of included studies for details. Individual trial sizes ranged between 42 and 3283 participants. Five trials were carried out in Australia (Rickard 2010; Rickard 2012; Van Donk 2009; Webster 2007; Webster 2008), and one each was carried out in Brazil (Vendramim 2018), China (Xu 2017), England (UK (Barker 2004)), and India (Nishanth 2009). Five of the trials were conducted in single-centre, acute inpatient settings (Barker 2004; Nishanth 2009; Rickard 2010; Webster 2007; Webster 2008), two were multicentred trials in large tertiary hospitals - one in Australia (Rickard 2012) and one in Brazil (Vendramim 2018); the Chinese trial was a cluster trial, which randomised 20 hospital wards (Xu 2017); and one trial was undertaken in a community setting (Van Donk 2009).

In eight trials (Barker 2004; Nishanth 2009; Rickard 2010; Rickard 2012; Vendramim 2018; Webster 2007; Webster 2008; Xu 2017), patients were included if they were receiving either continuous infusions or intermittent infusions for medication therapy, whereas the catheters in the Van Donk 2009 trial were used for intermittent medication therapy only. In seven trials (Rickard 2010; Rickard 2012; Van Donk 2009; Vendramim 2018; Webster 2007; Webster 2008; Xu 2017), the comparison was between routine care (planned 72- to 96-hour changes) and clinically indicated changes. Barker 2004 and Nishanth 2009 compared 48-hour changes with removal for clinical indications such as pain, catheter dislodgement, or phlebitis. 
Xu 2017; Rickard 2010 and Rickard 2012 defined CRBSI by using the CDC definition: a positive blood culture from a peripheral vein; clinical signs of infection; no other apparent source for the bloodstream infection except the IV catheter (in situ within 48 hours of the bloodstream infection); and a colonised IV catheter tip with the same organism identified in the blood (O'Grady 2011). In the Webster 2007 and Webster 2008 trials CRBSI was based on the isolation of a phenotypically identical organism from a catheter segment and a blood culture. None of the other trials provided definitions of CRBSI. Seven of the trials used a standard definition of two or more of the following: pain, warmth, erythema, swelling, or a palpable cord to define phlebitis (Barker 2004; Rickard 2010; Rickard 2012; Vendramim 2018; Webster 2007; Webster 2008; Xu 2017). Barker 2004 and Nishanth 2009 further classified phlebitis as either mild, moderate, or severe, depending on the area of erythema (Barker 2004), or on the number of symptoms (Nishanth 2009). Van Donk 2009 included the same symptoms as other trials but scored them as either one or two depending on the severity. A score of two or more was classified as phlebitis, consequently a participant may have had only one symptom, for example pain, to receive a positive diagnosis.

Nishanth 2009; Rickard 2010; Rickard 2012; Van Donk 2009; Vendramim 2018; Webster 2007; Webster 2008; and Xu 2017 reported power calculations but Barker 2004 did not. All of the studies had institutional ethical approval.

\section{Excluded studies}

We did not exclude any new studies in this update. The table Characteristics of excluded studies contains the reasons for excluding nine trials (Arnold 1977; Cobb 1992; Eyer 1990; Haddad 2006; Kerin 1991; May 1996; Nakae 2010; Panadero 2002; Rijnders 2004). In summary, two were very small studies involving the administration of peripheral parenteral nutrition. Neither trial compared straightforward routine replacement with clinically indicated removal (Kerin 1991; May 1996). Panadero 2002 compared one group that used the same catheter both intraoperatively and postoperatively with a group using two catheters, one during surgery and one postoperatively. Haddad 2006 compared 72-hour changes with 96-hour changes, and Cobb 1992; Eyer 1990; Nakae 2010; and Rijnders 2004 involved central venous catheters. The other excluded study was not an RCT (Arnold 1977).

\section{Risk of bias in included studies}

See individual 'Risk of bias' tables and Figure 2; Figure 3.

\section{Figure 2. 'Risk of bias' graph: review authors' judgements about each risk of bias item presented as percentages} across all included studies

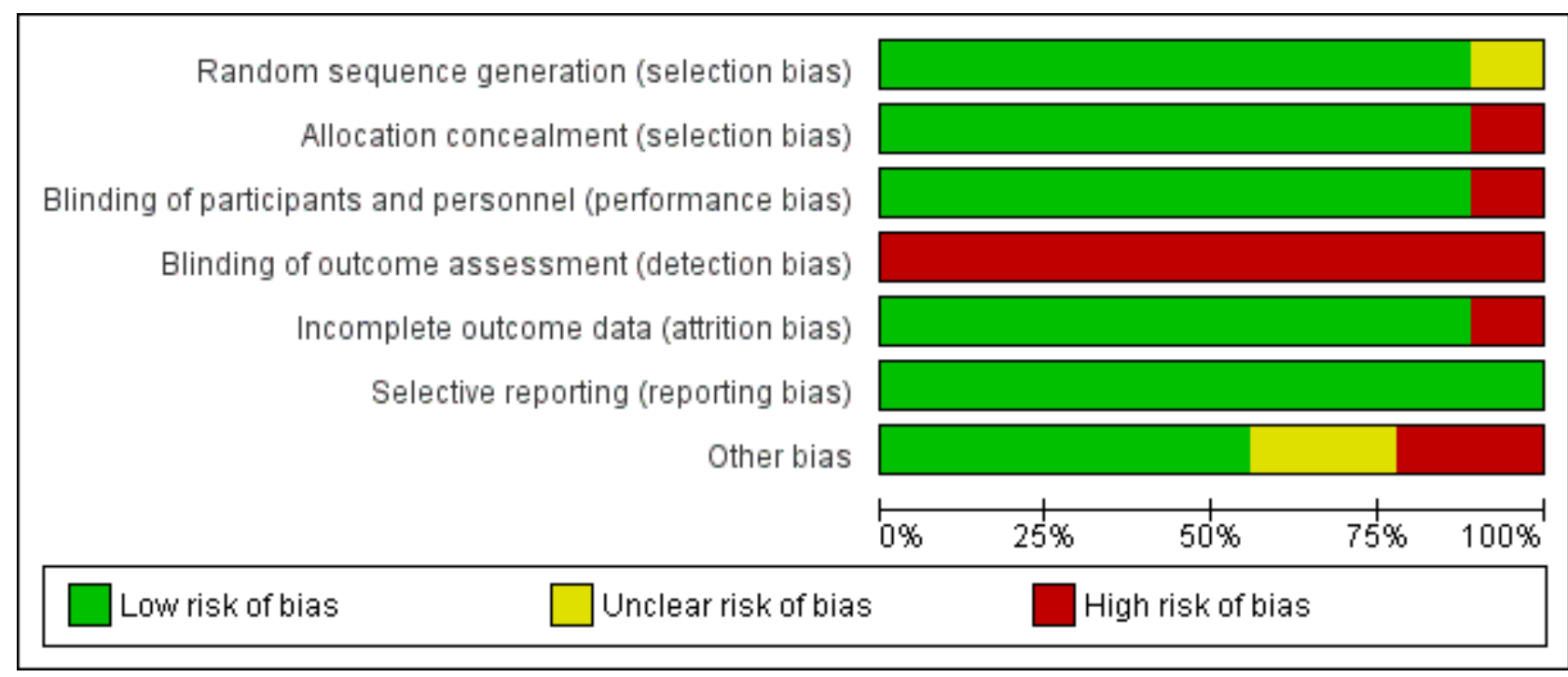


Figure 3. 'Risk of bias' summary: review authors' judgements about each risk of bias item for each included study

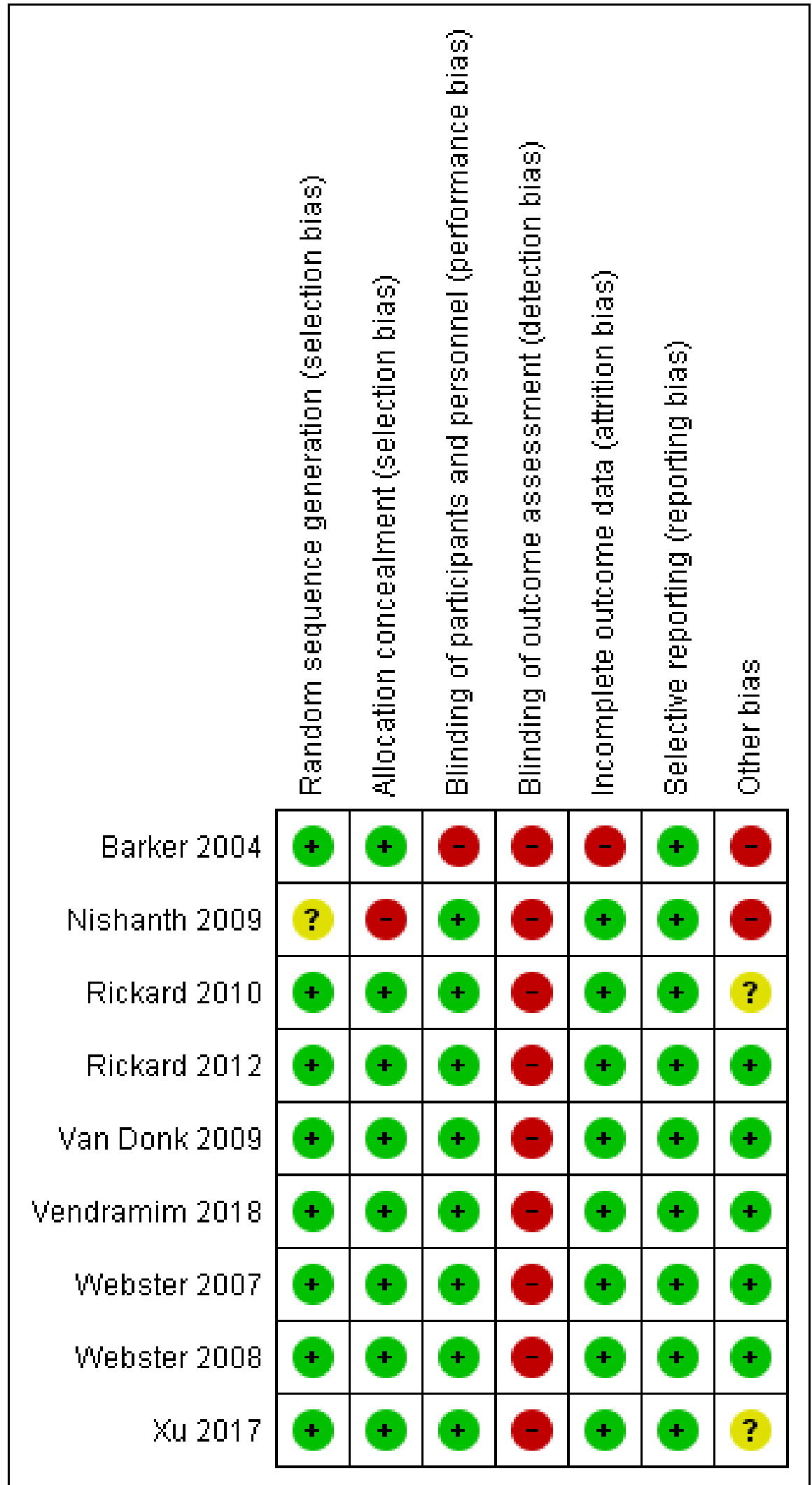




\section{Allocation}

\section{Generation of random allocation sequence}

Eight of the nine investigators reported that they used a computerbased sequence generator (Barker 2004; Nishanth 2009; Rickard 2010; Rickard 2012; Van Donk 2009; Vendramim 2018; Webster 2007; Webster 2008). Xu 2017 used a 'coin toss' to generate the random sequence. All studies were at low risk of bias except for Nishanth 2009, where it was unclear how they had generated the sequence.

\section{Allocation concealment}

Barker 2004; Nishanth 2009 and Van Donk 2009 used sealed envelopes for allocation concealment. Vendramim 2018 provided each ward with a sequentially numbered, randomised list. A coin toss in the Xu 2017 trial concealed allocation until randomisation. The remaining four trials used a central telephone or computerbased service (Rickard 2010; Rickard 2012; Webster 2007; Webster 2008). All studies were at low risk of bias except for Nishanth 2009, which was at high risk due to the investigators being responsible for allocation.

\section{Blinding}

It was not possible to blind either the participants or the healthcare providers in any of the trials but we did not believe that outcomes would be affected by this knowledge so we judged all trials to be at low risk of performance bias, except for Barker 2004 which we considered to be at high risk of bias because the investigator was involved in all stages of the study.

\section{Outcome assessment}

The chief investigator was directly involved in assessing outcomes in Barker 2004 and Nishanth 2009. In the Van Donk 2009; Vendramim 2018; Webster 2007 and Webster 2008 trials, nurses caring for the participant or a dedicated IV service nurse made the assessment. None of the nurses were blinded to the group allocation but nor were any of them associated with the trial. In Rickard 2010; Rickard 2012 and Xu 2017, a dedicated research nurse, who was also aware of the allocation, undertook outcome assessment. Because outcome assessment could not be blinded (except for CRBSI), we classified all trials as high risk of bias.

\section{Incomplete outcome data}

Barker 2004 did not provide a flow chart, so the numbers screened and eligible were unclear, nor did they report any dropouts. There was also an imbalance in the number of participants reported by group in this trial, which may indicate either a failure in the randomisation process in such a small trial or incomplete reporting. They did not report the number of protocol violations by group, and we judged Barker 2004 to be at high risk of attrition bias. The remaining eight studies were at low risk of bias as there was complete reporting and all provided a flow of participants through each stage and used intention-to-treat analysis (Nishanth 2009; Rickard 2010; Rickard 2012; Van Donk 2009; Vendramim
2018; Webster 2007; Webster 2008; Xu 2017). Nishanth 2009 did not report any protocol violations in the trial. In the Van Donk 2009; Vendramim 2018; Webster 2007; Webster 2008; and Xu 2017 trials, between $7 \%$ and approximately one third of the participants had protocol violations. Primarily, violations were in the routine replacement groups, where catheters were not replaced within the specified time period, reflecting day to day clinical practice.

\section{Selective reporting}

All studies were at low risk of reporting bias. Study protocols were available for seven trials and reporting followed pre-planned analyses (Rickard 2010; Rickard 2012; Van Donk 2009; Vendramim 2018; Webster 2007; Webster 2008; Xu 2017). Barker 2004 had only one outcome (phlebitis) and Nishanth 2009 reported on outcomes expected in this type of trial.

\section{Other potential sources of bias}

Five studies were at low risk of other bias (Rickard 2012; Van Donk 2009; Vendramim 2018; Webster 2007; Webster 2008). Barker 2004 used two definitions of phlebitis, one of which stated that two symptoms were necessary; yet it appears that they diagnosed erythema alone as phlebitis, with severity based on the area of inflammation; which leads to an assessment of high risk for other bias. The extreme results in Nishanth 2009, where $100 \%$ of participants in the clinically indicated group developed phlebitis compared with $9 \%$ in the two-day change group, suggests that chance or other unknown bias affected results in this small trial, to which we also gave a high-risk judgement. Two studies were at unclear risk of bias (Rickard 2010; Xu 2017). The Xu 2017 cluster-randomised trial analysed by individual not cluster; and significantly more participants in the routine-change group received IV antibiotics compared to the clinically indicated group in Rickard 2010.

\section{Effects of interventions}

See: Summary of findings for the main comparison Effects of clinically-indicated replacement compared to routine change of peripheral intravenous catheters

\section{Routine changes versus clinically indicated changes Catheter-related bloodstream infection (Analysis 1.1)}

Seven trials (7323 participants) assessed catheter-related bloodstream infection (CRBSI; Rickard 2010; Rickard 2012; Van Donk 2009; Vendramim 2018; Webster 2007; Webster 2008; Xu 2017). There were no reported CRBSIs in five of these trials (Rickard 2010; Van Donk 2009; Vendramim 2018; Webster 2007; Xu 2017). There is no clear difference in the incidence of CRBSI between the clinically indicated (1/3590) and routine-change (2/3733) groups. The RR was 0.61 but the confidence intervals $(\mathrm{Cl})$ were wide, creating uncertainty around the estimate $(95 \% \mathrm{Cl} 0.08$ to 4.68 ; Figure 4; Analysis 1.1). We judged the evidence as low certainty, as we downgraded two levels for serious imprecision. 
Figure 4. Forest plot of comparison 1, clinically indicated versus routine change, outcome: 1.1 Catheter-related bloodstream infection

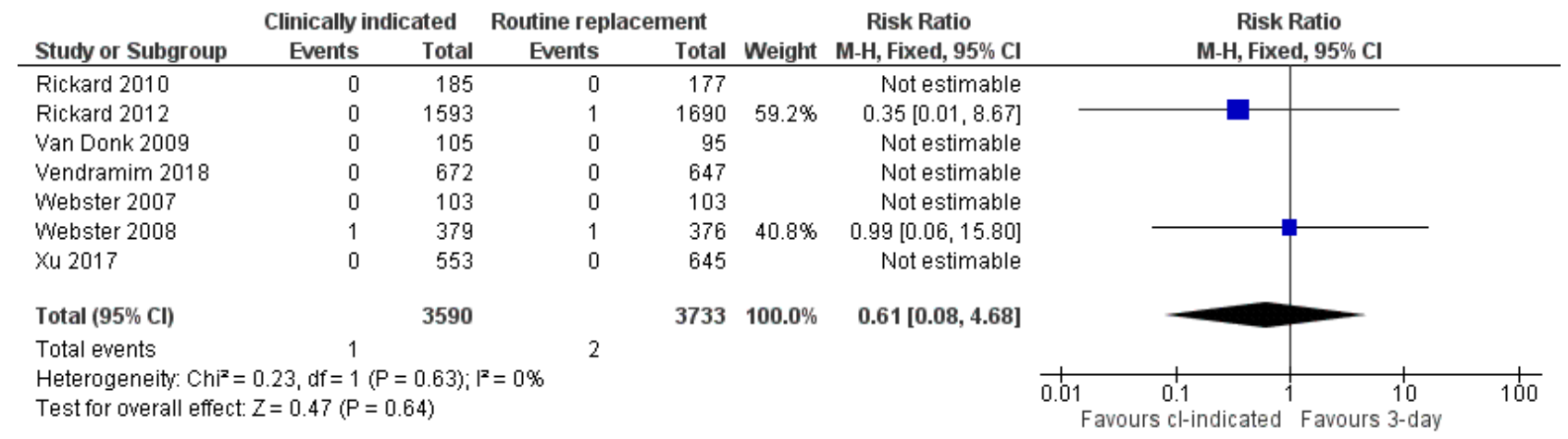

\section{Thrombophlebitis (Analysis 1.2 and Analysis 1.3)}

All of the included studies reported incidence of phlebitis; the initial analysis was based on 7412 participants. When results of all trials were combined, heterogeneity was $65 \%$. Consequently, we conducted a sensitivity analysis and removed the two trials with fewer than 100 participants (combined total $n=89$ ), both of which used a two-day replacement schedule and reported extreme results (Barker 2004; Nishanth 2009). Removing the two trials eliminated the heterogeneity $\left(I^{2}=0\right)$. We combined data from the remaining seven studies, with 7323 participants (Rickard 2010; Rickard 2012; Van Donk 2009; Vendramim 2018; Webster 2007; Webster 2008; Xu 2017). There was no clear difference in this outcome, whether catheters were changed according to clinical indications or routinely (RR $1.07,95 \% \mathrm{Cl} 0.93$ to 1.25 ; clinically indicated 317/3590; 3-day change 307/3733; moderate-certainty evidence, downgraded once for serious risk of bias (no blinding of outcome assessment in any of the trials)). The result was unaffected by whether the infusion was continuous or intermittent (Analysis 1.2; Figure 5).

\section{Figure 5. Forest plot of comparison 1, clinically indicated versus routine change, outcome: 1.2 Phlebitis}

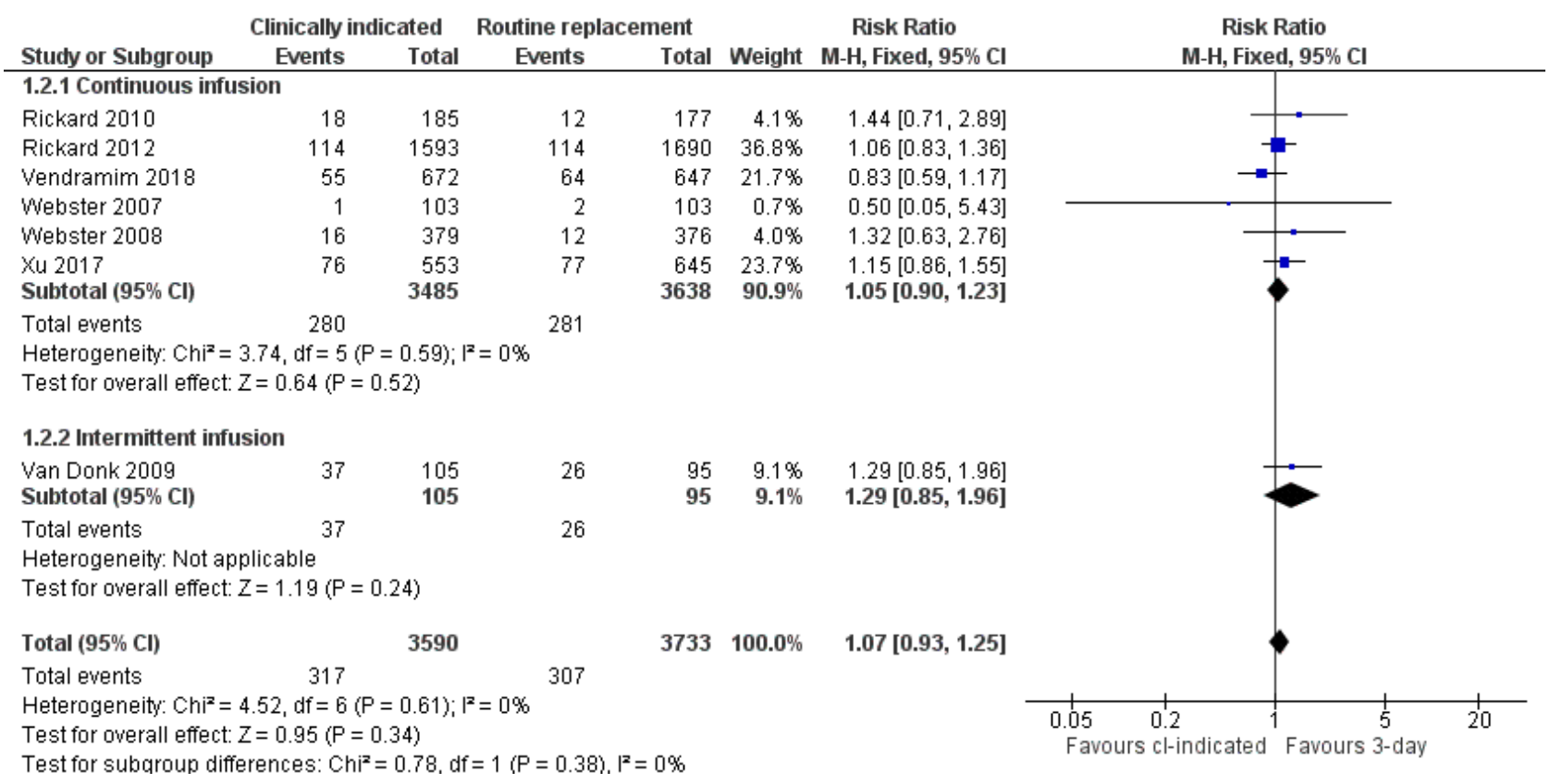

In the two trials using a two-day replacement schedule compared with clinically indicated changes (Barker 2004; Nishanth 2009), heterogeneity was over $60 \%$ so we did not combine results. In the first of these two trials, Barker 2004 reported that 11/26 (42.3\%) participants in the clinically indicated group developed phlebitis compared with $1 / 21(4.8 \%)$ in the two-day change group. Nishanth 2009 diagnosed all of the participants in the clinically indicated group $(21 / 21 ; 100.0 \%)$ with phlebitis and $2 / 21(9.5 \%)$ in the two-day group. We judged the evidence from these two trials to be very low certainty, downgraded two levels for very serious risk of bias and two levels for very serious imprecision.

Six of the trials provided phlebitis rates by number of device days (Rickard 2010; Rickard 2012; Van Donk 2009; Vendramim 2018; Webster 2007; Webster 2008), but again, there is no clear difference between groups for this outcome (RR 0.90, 95\% Cl 0.76 to 1.08 ; clinically indicated $248 / 17,251$; 3 -day change $236 / 15,458$; moderate-certainty evidence, downgraded once for serious risk of 
bias (no blind outcome assessment in any of the trials); Analysis 1.3;

Figure 6).

\section{Figure 6. Forest plot of comparison 1 clinically indicated versus routine change, outcome: 1.3 Phlebitis per device} days

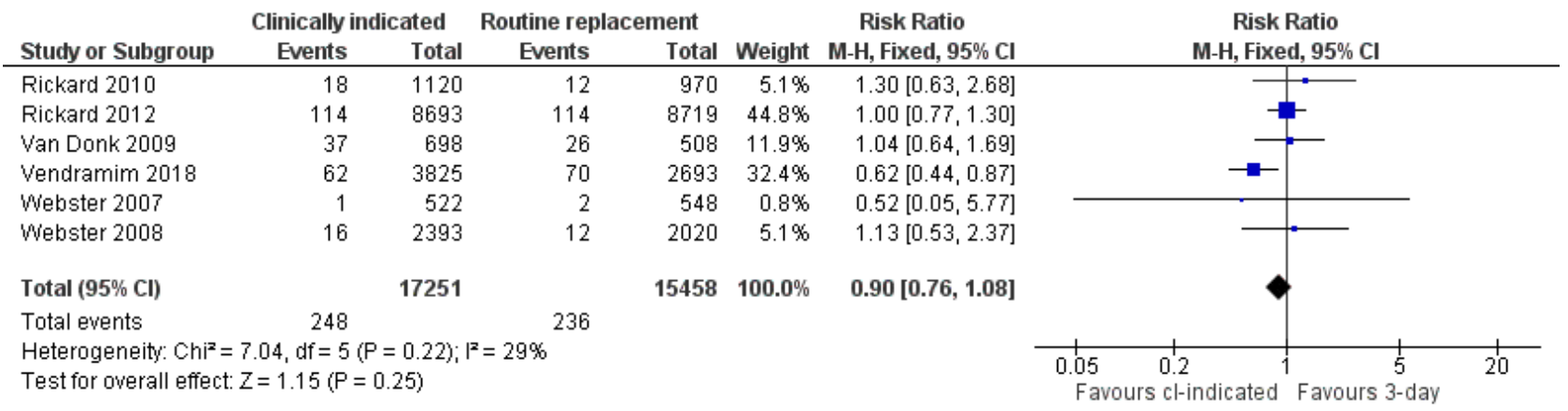

\section{All-cause bloodstream infection (Analysis 1.4)}

One trial assessed this outcome (Rickard 2012). We found no clear difference in the all-cause bloodstream infection rate between the two groups (RR $0.47,95 \% \mathrm{Cl} 0.15$ to 1.53; clinically indicated: 4/1593 $(0.02 \%)$; routine change $9 / 1690(0.05 \%))$. We judged the evidence as moderate certainty, downgraded one level for serious imprecision (Analysis 1.4).

\section{Cost (Analysis 1.5)}

Three trials (4244 participants) measured this outcome (Rickard 2012; Webster 2007; Webster 2008). Device-related costs were measured in Australian dollars (AUD). Clinically indicated removal probably reduces device-related costs by approximately AUD 7.00 per participant compared with routine removal (MD $-6.96,95 \% \mathrm{Cl}$ -9.05 to -4.86 ; moderate-certainty evidence, downgraded once for serious risk of bias (no blind outcome assessment in any of the trials); Analysis 1.5).

\section{Infiltration (Analysis 1.6)}

A total of six trials assessed infiltration in 7123 participants (Rickard 2010; Rickard 2012; Vendramim 2018; Webster 2007; Webster 2008; Xu 2017). Routine replacement probably reduces infiltration of fluid into surrounding tissues $(747 / 3638 ; 20.5 \%)$ compared with the clinically indicated group $(834 / 3485 ; 23.9 \%)$. The RR was 1.16 (95\% $\mathrm{Cl} 1.06$ to 1.26); moderate-certainty evidence, downgraded once for serious risk of bias (no blinding of outcome assessment in any of the trials; Analysis 1.6).

\section{Catheter occlusion/blockage (Analysis 1.7)}

We included seven of the nine trials, reporting on 7323 participants, in this analysis (Rickard 2010; Rickard 2012; Van Donk 2009; Vendramim 2018; Webster 2007; Webster 2008; Xu 2017). Rates of catheter failure due to blockage were probably lower in the routinereplacement group compared to the clinically indicated group (RR $1.14,95 \% \mathrm{Cl} 1.02$ to 1.27 ; routine-replacement group 519/3733 (13.9\%); clinically indicated group 560/3590 (15.6\%); Analysis 1.7). We judged the evidence as moderate certainty, as we downgraded once for serious risk of bias (no blinding of outcome assessment in any of the trials).

\section{Local infection (Analysis 1.8)}

Among the four trials measuring local infection (Rickard 2010; Rickard 2012; Webster 2007; Webster 2008), it is uncertain if there are differences in local infection rates between groups (RR 4.96, $95 \% \mathrm{Cl} 0.24$ to 102.98 ; clinically indicated 2/2260 (0.09\%); routine replacement $0 / 2346(0.0 \%)$; very-low-certainty evidence, downgraded one level for serious risk of bias (no blinding of outcome assessment in any of the trials) and two levels for very serious imprecision (Analysis 1.8)).

\section{Mortality (Analysis 1.9)}

One trial reported this outcome (Rickard 2012). In the clinically indicated group 4/1593 (0.25\%) died compared with 4/1690 (0.24\%) in the routine-replacement group (RR $1.06,95 \% \mathrm{Cl} 0.27$ to 4.23 ). We judged the evidence as low certainty, downgraded two levels for very serious imprecision (Analysis 1.9).

\section{Pain during infusion (Analysis 1.10)}

Vendramim 2018 (198 participants), measured pain on an 11-point scale (0 to 10), where higher scores represented higher levels of pain. There was no clear difference in device-related pain between clinically indicated and routine-removal groups. The mean pain score in the clinically indicated group was 4.6 (SD 3.0), compared with 5.2 (SD 3.0), in the routine replacement group (MD $-0.60,95 \%$ $\mathrm{Cl}-1.44$ to 0.24 ; low-certainty evidence, downgraded one level for serious risk of bias (no blinding of outcome assessment in any of the trials) and one-level for serious imprecision; Analysis 1.10).

The pre-planned outcomes 'number of catheter re-sites per patient', and 'satisfaction' were not reported by studies included in the review.

\section{Subgroup and sensitivity analysis}

We planned to conduct subgroup analyses on 1) Type of randomisation (truly randomised versus not reported); 2) Concealment of allocation (adequate versus not reported) and; 3) Statement of withdrawals and losses to follow-up in each group (stated versus not stated). However, there were too few studies in these subgroups to make any meaningful comparisons. Similarly, blinding was not possible in any of the studies. We did not conduct any of our pre-planned sensitivity analyses (except size of studies for the outcome 'phlebitis'), for similar reasons. 


\section{DISCUSSION}

\section{Summary of main results}

This systematic review analysed catheter-related bloodstream infection (CRBSI), phlebitis, other reasons for catheter failure, and cost with the intention of comparing routine catheter changes (at between two and four days) with replacing the catheter only if clinical signs warranting removal or replacement were apparent.

This update, which added a further two trials, confirms findings from the previous version of this review (Webster 2015). The primary outcomes suggest that patients are not adversely affected if the catheter is changed based on clinical indications rather than routinely. The rate of catheter-related bloodstream infection was similar in both groups, between $0.03 \%$ and $0.05 \%$, and comparable to that previously reported in prospective studies (Maki 2006). Because the incidence of peripheral intravenous (IV) CRBSI is very low, mounting a trial with sufficient power to show differences in CRBSI between catheters removed routinely or by clinical indication would be prohibitive. There is no clear difference in the phlebitis rate between groups whether rates are reported by the incidence per participant or by 1000 device days, which is a more clinically useful measure. Most cases of phlebitis are mild in nature, requiring no treatment or only removal of the catheter. There was no indication in our review that phlebitis was a precursor to bloodstream infection.

Catheter failure due to blockage was more frequent in the clinically indicated group. This could be expected; all catheters will fail eventually and will need to be replaced if treatment is ongoing. The outcome is not clinically meaningful, it is simply an indicator of the longer dwell times in the clinically indicated group. Since the 'treatment' for a blocked catheter is replacement of the catheter, it would not be of any benefit to the patient to replace the catheter earlier since it would not reduce the need for replacement, and would instead increase the chance of re-cannulation. Many catheters do not fail over the course of IV treatment, even with extended dwell times.

Cost was less, around AUD 7.00 per participant, in the clinically indicated group. This result was based on three studies and results were consistent and intuitively logical (fewer catheters, less clinician time and equipment). Although, this is a seemingly small amount, it corresponds to approximately $11 \%$ of catheterrelated expenditure, which may represent a considerable saving to organisations with high use of peripheral intravenous catheters (PIVC).

\section{Overall completeness and applicability of evidence}

Trials included in this systematic review directly addressed the review question and we were able to conduct a number of metaanalyses. Apart from Barker 2004 and Nishanth 2009, results from the other seven trials were quite similar, providing useful external validity. For example, participants were representative of those usually managed in healthcare, including patients in both acute and community settings. Additionally, measured outcomes were those important to clinicians and patients. It has been suggested that insertion and management by an IV team may explain the inefficacy of routine replacement to prevent complications (Maki 2008), yet we saw no effect in trials that had significant numbers inserted by an IV team (Webster 2007; Webster 2008), or trials where insertion was by the general medical and nursing staff (Rickard 2010; Rickard 2012), and none of the trials involved research nurses or IV teams providing post-insertion care of catheters. In all of the trials, except for Barker 2004 and Nishanth 2009, standard guidelines were followed for the control group; that is, catheters were changed at between 72 and 96 hours, reflecting usual care. Barker 2004 and Nishanth 2009 changed catheters every 48 hours. Only Rickard 2012 was powered to report on phlebitis alone, and some of the trials were very small. For example, the studies that showed statistically lower phlebitis rates in the clinically indicated group (Barker 2004; Nishanth 2009), involved just 47 and 42 participants respectively and showed differences between the control and intervention groups that were quite dissimilar to all of the other studies. Consequently, results of these two trials should be interpreted with caution, particularly results from Nishanth 2009, where all participants in the clinically indicated group developed phlebitis compared with none in the two-day change group. It seems unlikely that these results would have occurred by chance but correspondence with trial authors shed no further light on these extreme results. There are no other published papers showing phlebitis rates of $100 \%$.

Five of the nine included trials were conducted in Australia; this imbalance is difficult to understand but the two additional studies, one from China (Xu 2017), and one from Brazil (Vendramim 2018), provide added diversity to the evidence and increase external validity. It would be useful to see similar studies from other healthcare settings to test the robustness of results from this review.

Only Vendramim 2018 assessed levels of pain, and none of the trials measured device-related satisfaction or number of catheter re-sites per participant. These outcomes would be a useful addition to any future trial.

\section{Quality of the evidence}

See Summary of findings for the main comparison

Overall we found the quality of evidence for most outcomes to be of moderate to low quality, primarily due to risk of bias (particularly non-blinding of the outcome assessor), and imprecision. Imprecision was due in some cases, such as 'pain', to few participants but in other cases, such as mortality, to few events.

\section{Limitations in study design and implementation}

We assessed risk of bias according to six components: sequence generation, allocation concealment, blinding, selective outcome reporting, incomplete follow-up, and other potential biases. All of the studies (except Nishanth 2009), avoided selection bias and ensured allocation concealment. We rated the evidence for methodological quality of most of the outcomes as moderate. It was not possible to blind the intervention in any of the trials because it was necessary to identify the catheter as either 'routine change' or 'clinically indicated', to prevent inadvertent routine replacement of catheters in the intervention group. It is unclear if this had any bearing on outcomes but we decided to downgrade one level for all outcomes except CRBSI, where a blinded microbiologist diagnosed the condition. However, as one trial author noted, it is routine practice to record reasons for removal of an IV catheter in the medical record, and it is unlikely that such entries would be falsified based on group allocation (Webster 2008). In Barker 2004 and Nishanth 2009, the investigator 
was directly involved in diagnosing phlebitis; in all of the other studies either medical staff, ward nurses, IV therapy staff, or research nurses evaluated the outcomes.

\section{Indirectness of evidence}

All of the trials compared routine changes with clinically indicated changes. However, seven trials used a three to four-day change schedule and two trials changed catheters every two days. Consequently, three to four-day results may provide indirect evidence for two-day changes, conversely twoday changes provide indirect evidence for a three to fourday change schedule. Additionally, only Nishanth 2009 included participants who were from a low-income country and who were, "usually asthenic, many underhydrated/dehydrated on admission" (personal correspondence), so the evidence may be regarded as indirect for these types of patients.

\section{Unexplained heterogeneity or inconsistency of results}

When we combined results of studies that investigated the effect of different catheter replacement schedules on phlebitis, the heterogeneity was high. This was probably due to the different schedules for the routine catheter changes or population differences, or both. Small sample sizes may also have contributed to the extreme results, which caused the heterogeneity. We tested these assumptions by performing a sensitivity analysis, removing two of the nine studies. Results of all trials are presented in the review text and of seven trials in the 'Summary of findings' table (Summary of findings for the main comparison).

\section{Imprecision of results}

Confidence intervals were wide in the pooled outcomes of CRBSI, all-cause blood stream infection, local infection, mortality and pain, indicating a high level of uncertainty around the effect size. Further research is therefore very likely to have an important impact on the confidence in the estimate of effect for these outcomes.

\section{Publication bias}

We feel confident that our comprehensive electronic searches, handsearching, and searches of large clinical trials databases, identified all existing, published, randomised controlled trials addressing the review question. We also have an established international network of researchers in the field of vascular access, who alert us to new trials. We would have developed a funnel plot to detect reporting bias, if we had included more than 10 studies in the review.

\section{Potential biases in the review process}

Although the review authors were investigators in one or more of the included trials, we followed clearly described procedures to prevent potential biases in the review process. We conducted a careful literature search and the methods we used were transparent and reproducible. None of the review authors has any conflict of interests.

\section{Agreements and disagreements with other studies or reviews}

Our results concur with several, prospective observational studies, which found no additional risk in extending intravenous device (IVD) dwell times (Abolfotouh 2014; Catney 2001; White 2001).
In addition, two implementation studies, which changed their policies to replacing PIVCs only if clinical indications were present, showed no increase in rates of PIVC-related infection (Bolton 2015; De Vries 2016). In addition, Bolton 2015 reported a significant cost saving with a $25 \%$ stock reduction. Similarly, in the De Vries 2016 study, peripheral line start kits were reduced by $48 \%$ in the year following the policy change. Two recently published reviews, assessing the effect of changing PIVCs only where a clinical indication exists also concurred with our results (Morrison 2015; Patel 2017). Importantly, international and other guidelines have been changed to reflect the results of this review (Gorski 2016; Ho 2011; Loveday 2014). One of our outcomes was catheter-related blood stream infection (CRBSI). We included seven RCTs (over 7000 participants), and found no evidence that dwell time had any effect on this outcome. In contrast, in another systematic review, Mermel 2017 suggested that longer dwell times resulted in higher CRBSI rates. The reason for the discrepancy between the two reviews is the inclusion criteria. We included only RCTs whereas Mermel 2017 included incidence studies, quality improvement studies, quasiexperimental designs and a number of RCTs where difference in dwell time was not the focus of the study. When participants are not randomised, or not randomised for the purpose of assessing the effect of dwell time on catheter-related outcomes, a potential for bias exists. For example, the sickest participants, those most likely to develop a CRBSI, are also those who would be expected to have their catheters in place for longer periods. Randomisation ensures risk factors that may affect the outcome, are equally distributed between groups.

\section{AUTHORS' CONCLUSIONS}

\section{Implications for practice}

This review update found moderate to low-certainty evidence of no clear difference in rates of catheter-related bloodstream infection (CRBSI), thrombophlebitis, all-cause bloodstream infection, mortality or pain between clinically indicated or routine replacement of peripheral intravenous catheters. We are uncertain if local infection is reduced or increased when catheters are changed when clinically indicated. There is moderate-certainty evidence that infiltration and catheter blockage is probably lower when PIVC are changed routinely; and moderate-certainty evidence that clinically indicated removal probably reduces device-related costs. The consistency in these results, which include two very large multisite studies, indicate that healthcare organisations should consider changing to a policy whereby catheters are changed only if there is a clinical indication to do so, for example, if there were signs of infection, blockage or infiltration. This would provide significant cost savings and would also be welcomed by patients, who would be spared the unnecessary pain of routine re-sites in the absence of clinical indications. Time spent by busy clinical staff on this intervention would also be reduced. To minimise peripheral catheter-related complications, the insertion site should be inspected at each shift change and the catheter removed if signs of inflammation, infiltration, or blockage are present, or as soon as therapy is completed.

\section{Implications for research}

Based on results from the meta-analyses in this review, a sample size of greater than 25,000 participants would be required to show clear differences between groups for the most important outcomes in this review, that is CRBSI and phlebitis. Consequently, it is 
unlikely that such a trial is warranted, given the low event rate for CRBSI and the very high number needed to treat (almost 1700) for one patient to avoid phlebitis.

\section{ACKNOWLEDGEMENTS}

We acknowledge the input of Dr Karen New in previous versions of the review. We are grateful to Marlene Stewart, Cochrane Vascular Managing Editor, for her support and speedy responses, and to the editors Mr Paul Tisi and Dr Jackie Price for their useful comments. 


\section{R E F E R E N C E S}

\section{References to studies included in this review}

Barker 2004 \{published and unpublished data\}

Barker P, Anderson AD, Macfie J. Randomised clinical trial of elective re-siting of intravenous cannulae. Annals of the Royal College of Surgeons of England 2004;86(4):281-3.

\section{Nishanth 2009 \{published data only\}}

Nishanth S, Sivaram G, Kalayarasan R, Kate V, Ananthakrishnan N. Does elective re-siting of intravenous cannulae decrease peripheral thrombophlebitis? A randomized controlled study. The International Medical Journal of India 2009;22(2):60-2.

\section{Rickard 2010 \{published and unpublished data\}}

Rickard CM, McCann D, Munnings J, McGrail M. Routine resite of peripheral intravenous devices every 3 days did not reduce complications compared with clinically indicated re-site: a randomised controlled trial. BMC Medicine 2010;8:53.

\section{Rickard 2012 \{published and unpublished data\}}

Rickard CM. Clinically indicated and routine replacement of peripheral IV catheters did not differ for phlebitis. Annals of Internal Medicine 2013;158:JC8. Ref ID:81.

* Rickard CM, Webster J, Wallis MC, Marsh N, McGrail MR, French $V$, et al. Routine versus clinically indicated replacement of peripheral intravenous catheters: a randomised equivalence trial. Lancet 2012;380(9847):1066-74.

Tuffaha HW, Rickard CM, Webster J, Marsh N, Gordon L, Wallis M, et al. Cost-effectiveness analysis of clinically indicated versus routine replacement of peripheral intravenous catheters. Applied Economics and Health Policy 2014;12:51-8.

\section{Van Donk 2009 \{published and unpublished data\}}

Van Donk P, Rickard CM, McGrail MR, Doolan G. Routine replacement versus clinical monitoring of peripheral intravenous catheters in a regional hospital in the home program: a randomized controlled trial. Infection Control and Hospital Epidemiology 2009;30(9):915-7.

\section{Vendramim 2018 \{unpublished data only\}}

Vendramim P. ResPeCt- removal of peripheral intravenous catheters according to clinical signs or every 96 hours: randomized, controlled and non-inferiority trial. Unpublished (final communication with trial author 1 August 2018).

\section{Webster 2007 \{published and unpublished data\}}

Webster J, Lloyd S, Hopkins T, Osborne S, Yaxley M. Developing a research base for intravenous peripheral cannula resites (DRIP trial). A randomised controlled trial of hospital in-patients. International Journal of Nursing Studies 2007;44(5):664-71.

\section{Webster 2008 \{published and unpublished data\}}

Webster J, Clarke S, Paterson D, Hutton A, Van Dyke S, Gale C, et al. Routine care of peripheral intravenous catheters versus clinically indicated replacement: randomised controlled trial. BMJ 2008;337:a339.
Xu 2017 \{published data only\}

Xu L, Hu Y, Huang X, Fu J, Zhang J. Clinically indicated replacement versus routine replacement of peripheral venous catheters in adults: a nonblinded, cluster-randomized trial in China. International Journal of Nursing Practice 2017;23:doi: 10.1111/ijn.12595.

\section{References to studies excluded from this review}

\section{Arnold 1977 \{published data only\}}

Arnold RE, Elliot EK, Holmes BH. The importance of frequent examination of infusion sites in preventing postinfusion phlebitis. Surgery, Gynecology and Obstetrics 1977;145(1):19-20.

Cobb 1992 \{published data only\}

Cobb DK, High KP, Sawyer RG, Sable CA, Adams RB, Lindley DA, et al. A controlled trial of scheduled replacement of central venous and pulmonary-artery catheters. New England Journal of Medicine 1992;327(15):1062-8.

Eyer 1990 \{published data only\}

Eyer S, Brummitt C, Crossley K, Siegel R, Cerra F. Catheterrelated sepsis: prospective, randomized study of three methods of long-term catheter maintenance. Critical Care Medicine 1990;18(10):1073-9.

\section{Haddad 2006 \{published data only\}}

Haddad FG, Waked CH, Zein EF. Peripheral venous catheter inflammation. A randomized prospective trial. Le Journal Médical Libanais 2006;54:139-45.

Kerin 1991 \{published data only\}

Kerin MJ, Pickford IR, Jaeger H, Couse NF, Mitchell CJ, Macfie J. A prospective and randomised study comparing the incidence of infusion phlebitis during continuous and cyclic peripheral parenteral nutrition. Clinical Nutrition 1991;10(6):315-9.

\section{May 1996 \{published data only\}}

May J, Murchan P, MacFie J, Sedman P, Donat P, Palmer D, et al. Prospective study of the aetiology of infusion phlebitis and line failure during peripheral parenteral nutrition. British Journal of Surgery 1996;83(8):1091-4.

\section{Nakae 2010 \{published data only\}}

Nakae H, Igarashi T, Tajimi K. Catheter-related infections via temporary vascular access catheters: a randomized prospective study. Artificial Organs 2010;34(3):E72-6.

\section{Panadero 2002 \{published data only\}}

Panadero A, lohom G, Taj J, Mackay N, Shorten G. A dedicated intravenous cannula for postoperative use. Effect on incidence and severity of phlebitis. Anaesthesia 2002;57(9):921-5.

\section{Rijnders 2004 \{published data only\}}

Rijnders BJ, Peetermans WE, Verwaest C, Wilmer A, Van Wijngaerden $\mathrm{E}$. Watchful waiting versus immediate catheter removal in ICU patients with suspected catheter- 
related infection: a randomized trial. Intensive Care Medicine 2004;30(6):1073-80.

\section{References to studies awaiting assessment}

Chin 2018 \{published data only\}

Chin LY, Walsh TA, Van Haltren K, Hayden L, Davies-Tuck M, Malhotra A. Elective replacement of intravenous cannula in newborn infants: a randomised control trial. Journal of Paediatrics and Child Health 2018;54(Suppl 1):12.

\section{Additional references}

\section{Abolfotouh 2014}

Abolfotouh MA, Salam M, Bani-Mustafa A, White D, Balkhy HH. Prospective study of incidence and predictors of peripheral intravenous catheter-induced complications. Therapeutics and Clinical Risk Management 2014;10:993-1001.

\section{Bolton 2015}

Bolton D. Clinically indicated replacement of peripheral cannulas. British Journal of Nursing 2015;24:S4-S12.

\section{Bregenzer 1998}

Bregenzer T, Conen D, Sakmann P, Widmer AF. Is routine replacement of peripheral intravenous catheters necessary?. Archives of Internal Medicine 1998;158:51-6.

\section{Catney 2001}

Catney MR, Hillis S, Wakefield B, Simpson L, Domino L, Keller S, et al. Relationship between peripheral intravenous catheter dwell time and the development of phlebitis and infiltration. Journal of Infusion Nursing 2001;24(5):332-41.

\section{Cornely 2002}

Cornely OA, Bethe U, Pauls R, Waldschmidt D. Peripheral Teflon catheters: factors determining incidence of phlebitis and duration of cannulation. Infection Control and Hospital Epidemiology 2002;23:249-53.

\section{De Vries 2016}

De Vries M, Valentine M, Mancos P. Protected clinical indication of peripheral intravenous lines: successful implementation. Journal of the Association of Vascular Access 2016;21:89-92.

\section{Deeks 2017}

Deeks JJ, Higgins JP, Altman DG (editors) on behalf of the Cochrane Statistical Methods Group. Chapter 9: Analysing data and undertaking meta-analyses. In: Higgins JP, Churchill R, Chandler J, Cumpston MS (editors), Cochrane Handbook for Systematic Reviews of Interventions version 5.2.0 (updated June 2017), Cochrane, 2017. Available from training.cochrane.org/handbook.

\section{Everitt 1997}

Everitt NJ, Krupowicz DW, Evans JA, McMahon MJ. Ultrasonographic investigation of the pathogenesis of infusion thrombophlebitis. British Journal of Surgery 1997;84:642-5.

\section{Gahlot 2014}

Gahlot R, Nigam C, Kumar V, Yadav G, Anupurba S. Catheterrelated bloodstream infections. International Journal of Critical Illness and Injury Science 2014;4:162-7.

\section{Gorski 2016}

Gorski L, Hadaway L, Hagle ME, McGoldrick M, Orr M, Doellman D. Infusion therapy standards of practice. Journal of Infusion Nursing 2016;39:S91.

\section{Hadaway 2012}

Hadaway L. Short peripheral intravenous catheters and infections. Journal of Infusion Nursing 2012;35(4):230-40.

\section{Higgins 2003}

Higgins JP, Thompson SG, Deeks JJ, Altman DG. Measuring inconsistency in meta-analyses. BMJ 2003;327:557-60.

\section{Higgins 2011a}

Higgins JP, Deeks JJ, Altman DG (editors). Chapter 16: Special topics in statistics. In: Higgins JP, Green S, editor(s). Cochrane Handbook for Systematic Reviews of Interventions. Version 5.1.0 (updated March 2011). The Cochrane Collaboration, 2011. Available from handbook.cochrane.org.

\section{Higgins 2011b}

Higgins JP, Deeks JJ (editors). Chapter 7: Selecting studies and collecting data. In: Higgins JP, Green S, editor(s), Cochrane Handbook for Systematic Reviews of Interventions Version 5.1.0 (updated March 2011). The Cochrane Collaboration, 2011. Available from handbook.cochrane.org.

\section{Higgins 2017}

Higgins JP, Altman DG, Sterne JA (editors). Chapter 8: Assessing risk of bias in included studies. In: Higgins JP, Churchill R, Chandler J, Cumpston MS (editors), Cochrane Handbook for Systematic Reviews of Interventions version 5.2.0 (updated June2017), Cochrane, 2017. Available from training.cochrane.org/handbook.

\section{Ho 2011}

Ho KHM, Cheung DSK. Guidelines on timing in replacing peripheral intravenous catheters. Journal of Clinical Nursing 2011;21(11-12):1499-506.

\section{Homer 1998}

Homer LD, Holmes KR. Risks associated with 72- and 96hour peripheral intravenous catheter dwell times. Journal of Intravenous Nursing 1998;21:301-5.

\section{Infusion Nurses Society 2011}

Infusion Nurses Society. Infusion Nursing Standards of Practice. Journal of Infusion Nursing 2011;34(1S):S57.

\section{Lefebvre 2011}

Lefebvre C, Manheimer E, Glanville J. Chapter 6: Searching for studies. In: Higgins JP, Green S, editor(s). Cochrane Handbook for Systematic Reviews of Interventions Version 5.1.0 (updated March 2011). The Cochrane Collaboration, 2011. Available from handbook.cochrane.org. 


\section{Liberati 2009}

Liberati A, Altman DG, Tetzlaff J, Mulrow C, Gotzsche PC, loannidis JP, et al. The PRISMA statement for reporting systematic reviews and meta-analyses of studies that evaluate health care interventions: explanation and elaboration. $B M J$ 2009;339:b2700.

\section{Loveday 2014}

Loveday HP, Wilson JA, Pratt RJ, Golsorkhi M, Tingle A, Bak A, et al. epic3: National Evidence-based guidelines for preventing healthcare-associated infections. Journal of Hospital Infection 2014;86 Suppl 1:S1-70.

\section{Maddox 1977}

Maddox RR, Rush DR, Rapp RP, Foster TS, Mazella V, McKean HE. Double-blind study to investigate methods to prevent cephalothin-induced phlebitis. American Journal of Hospital Pharmacy 1977;34:29-34.

\section{Maki 1991}

Maki DG, Ringer M. Risk factors for infusion-related phlebitis with small peripheral venous catheters. A randomized controlled trial. Annals of Internal Medicine 1991;114:845-54.

\section{Maki 2006}

Maki DG, Kluger DM, Crnich CJ. The risk of bloodstream infection in adults with different intravascular devices: a systematic review of 200 published prospective studies. Mayo Clinic Proceedings 2006;81(9):1159-71.

\section{Maki 2008}

Maki DG. Improving the safety of peripheral intravenous catheters. BMJ 2008;337(7662):122-3.

\section{Marsh 2018a}

Marsh N, Webster J, Ullman A, Mihala G, Cooke M, Rickard CM. The incidence of peripheral intravenous catheter failure and complications within the adult population: a systematic review. BMJ 2018; Vol. (in editorial process).

\section{Marsh 2018b}

Marsh N, Webster J, Larsen E, Cooke M, Mihala G, Rickard C. Observational study of peripheral intravenous catheter outcomes in adult hospitalized patients: a multivariable analysis of peripheral intravenous catheter failure. Journal of Hospital Medicine 2018;13:83-9.

\section{Mermel 2017}

Mermel LA. Short-term peripheral venous catheterrelated blood stream infection. Clinical Infectious Diseases 2017;65(10):1757-62.

\section{Monreal 1999}

Monreal M, Quilez F, Rey-Joly C, Vega J, Torres T, Valero P, et al. Infusion phlebitis in patients with acute pneumonia: a prospective study. Chest 1999;115:1576-80.

\section{Morrison 2015}

Morrison K, Holt KE. The effectiveness of clinically indicated replacement of peripheral intravenous catheters: an evidence review with implications for clinical practice. Worldviews Evidence Based Nursing 2015;12:187-98.

\section{O'Grady 2011}

O'Grady NP, Alexander M, Burns LA, Dellinger EP, Garland J, Heard SO, et al. 2011 Guidelines for the prevention of intravascular catheter-related infections. (accessed 23 August 2018).

\section{Patel 2017}

Patel SA, Alebich MM, Feldman LS. Routine replacement of peripheral intravenous catheters. Journal of Hospital Medicine 2017;12:42-5

\section{Ray-Barruel 2014}

Ray-Barruel G, Polit DF, Murfield JE, Rickard CM. Infusion phlebitis assessment measures: a systematic review. Journal of Evaluation in Clinical Practice 2014;20:191-202.

\section{Review Manager 2014 [Computer program]}

Nordic Cochrane Centre, The Cochrane Collaboration. Review Manager 5 (RevMan 5). Version 5.3. Copenhagen: Nordic Cochrane Centre, The Cochrane Collaboration, 2014.

\section{Rickard 2018}

Rickard CM, Webster J, Runnegar N, Larsen E, McGrail MR, Fullerton $\mathrm{F}$, et al. Dressings and securements for the prevention of peripheral intravenous catheter failure in adults (SAVE): a pragmatic,randomised controlled, superiority trial. Lancet 2018;392:419-30. [DOI: 10.1016/S0140-6736(18)31380-1]

\section{Schünemann 2017}

Schünemann HJ, Oxman AD, Vist GE, Higgins JP, Deeks JJ, Glasziou P, et al. on behalf of the Cochrane Applicability and Recommendations Methods Group. Chapter 12: Interpreting results and drawing conclusions. In: Higgins JP, Churchill R, Chandler J, Cumpston MS (editors), Cochrane Handbook for Systematic Reviews of Interventions version 5.2.0 (updated June 2017). Cochrane, 2017. Available from training.cochrane.org/handbook.

\section{Sterne 2017}

Sterne JA, Egger M, Moher D, Boutron I (editors). Chapter 10: Addressing reporting biases. In: Higgins JP, Churchill R, Chandler J, Cumpston MS (editors), Cochrane Handbook for Systematic Reviews of Interventions version 5.2.0 (updated June 2017), Cochrane, 2017. Available from training.cochrane.org/handbook.

\section{Tan 2016}

Tan PC, Mackeen A, Khong SY, Omar SZ, Azmi MA. Peripheral intravenous catheterisation in obstetric patients in the hand or forearm vein: a randomised trial. Scientific reports 2016;6:23223.

\section{Tuffaha 2014a}

Tuffaha HW, Rickard CM, Webster J, Marsh N, Gordon L, Wallis M, et al. Cost-effectiveness analysis of clinically indicated versus routine replacement of peripheral intravenous catheters. Applied Economics and Health Policy 2014;12:51-8. 


\section{Tuffaha 2014b}

Tuffaha HW, Rickard CM, Inwood S, Gordon L, Scuffham P. The epic3 recommendation that clinically indicated replacement of peripheral venous catheters is safe and cost-saving: how much would the NHS save?. Journal of Hospital Infection 2014;87(3):183-4.

\section{Uslusoy 2008}

Uslusoy E, Mete S. Predisposing factors to phlebitis in patients with peripheral intravenous catheters: a descriptive study. Journal of the American Academy of Nurse Practitioners 2008;20:172-80.

\section{White 2001}

White SA. Peripheral intravenous therapy-related phlebitis rates in an adult population. Journal of Intravenous Nursing 2001;24:19-24.

\section{References to other published versions of this review}

\section{Webster 2009}

Webster J, Osborne S, Hall J, Rickard C. Clinically indicated replacement versus routine replacement of peripheral venous

\section{CHARACTERISTICS OF STUDIES}

Characteristics of included studies [ordered by study ID] catheters. Cochrane Database of Systematic Reviews 2009, Issue 2. [DOI: 10.1002/14651858.CD007798]

\section{Webster 2010}

Webster J, Osborne S, Rickard C, Hall J. Clinically-indicated replacement versus routine replacement of peripheral venous catheters. Cochrane Database of Systematic Reviews 2010, Issue 3. [DOI: 10.1002/14651858.CD007798.pub2]

\section{Webster 2013}

Webster J, Osborne S, Rickard CM, New K. Clinically-indicated replacement versus routine replacement of peripheral venous catheters. Cochrane Database of Systematic Reviews 2013, Issue 4. [DOI: 10.1002/14651858.CD007798.pub3]

\section{Webster 2015}

Webster J, Osborne S, Rickard CM, New K. Clinically-indicated replacement versus routine replacement of peripheral venous catheters. Cochrane Database of Systematic Reviews 2015, Issue 8. [DOI: 10.1002/14651858.CD007798.pub4]

* Indicates the major publication for the study

Barker 2004

\begin{tabular}{l} 
Study design: single-centre RCT \\
Method of randomisation: computer-generated \\
Concealment of allocation: sealed envelopes \\
\hline
\end{tabular}

Participants

Country: England, UK

Number: 47 patients in general medical or surgical wards. Clinically indicated: 43 catheters were inserted in 26 participants. Routine replacement: 41 catheters were inserted in 21 participants

Age: clinically indicated 60.5 years (15.5); routine replacement 62.7 years (18.2)

Sex (M/F): clinically indicated 15/11; routine replacement $14 / 7$

Inclusion criteria: hospital inpatients receiving crystalloids and drugs

Exclusion criteria: not stated

Interventions

Clinically indicated: catheters were removed if the site became painful, the catheter dislodged or there were signs of PVT

Routine replacement: catheters were replaced every $48 \mathrm{~h}$

Outcomes

Primary: incidence of PVT defined as "the development of two or more of the following: pain, erythema, swelling, excessive warmth or a palpable venous cord"

Notes

PVT was defined as "the development of two or more of the following: pain, erythema, swelling, excessive warmth or a palpable venous cord". However, in the discussion, the trial author stated that "even a small area of erythema was recorded as phlebitis" (i.e. only 1 sign).

It is unclear what proportion of participants were on continuous infusion. 
Barker 2004 (Continued)

Catheters were inserted "at the instruction of the principal investigator".

"All patients were reviewed daily by the principal investigator, and examined for signs of PVT at the current and all previous infusion sites".

\section{Risk of bias}

\begin{tabular}{|c|c|c|}
\hline Bias & Authors' judgement & Support for judgement \\
\hline $\begin{array}{l}\text { Random sequence genera- } \\
\text { tion (selection bias) }\end{array}$ & Low risk & Comment: computer-generated (personal communication with trial author) \\
\hline $\begin{array}{l}\text { Allocation concealment } \\
\text { (selection bias) }\end{array}$ & Low risk & Comment: sealed envelopes (personal communication with trial author) \\
\hline $\begin{array}{l}\text { Blinding of participants } \\
\text { and personnel (perfor- }\end{array}$ & High risk & $\begin{array}{l}\text { Evidence: "Forty-seven patients were included in this randomised, controlled, } \\
\text { unblinded study" }\end{array}$ \\
\hline All outcomes & & $\begin{array}{l}\text { Comment: classified as high risk because the investigator was involved in all } \\
\text { stages of the study }\end{array}$ \\
\hline $\begin{array}{l}\text { Blinding of outcome as- } \\
\text { sessment (detection bias) } \\
\text { All outcomes }\end{array}$ & High risk & $\begin{array}{l}\text { Evidence: "Forty-seven patients were included in this randomised, controlled, } \\
\text { unblinded study" }\end{array}$ \\
\hline $\begin{array}{l}\text { Incomplete outcome data } \\
\text { (attrition bias) } \\
\text { All outcomes }\end{array}$ & High risk & $\begin{array}{l}\text { Comment: in this small sample, there were five fewer participants in the rou- } \\
\text { tine replacement group. No explanation was provided for the unequal sample } \\
\text { size. No dropouts or loss to follow-up were reported. }\end{array}$ \\
\hline $\begin{array}{l}\text { Selective reporting (re- } \\
\text { porting bias) }\end{array}$ & Low risk & Comment: Phlebitis was the only outcome planned. \\
\hline \multirow[t]{2}{*}{ Other bias } & High risk & $\begin{array}{l}\text { Comment: the chief investigator allocated participants and was responsible } \\
\text { for outcome evaluation. }\end{array}$ \\
\hline & & No sample size calculation \\
\hline
\end{tabular}

Nishanth 2009

\begin{tabular}{ll}
\hline Methods & Study design: single-centre RCT \\
Method of randomisation: not stated. \\
Concealment of allocation: sequentially numbered, sealed envelopes \\
Country: India \\
Number: 42 patients in surgical wards. Clinically indicated: 21. Routine replacement: 21 \\
Age: clinically indicated 40.2 years $(15.0)$; routine replacement 42.9 years $(15.0)$ \\
Sex (M/F): clinically indicated $17 / 4$; routine replacement $16 / 5$ \\
Inclusion criteria: hospital inpatients admitted for major abdominal surgery \\
Exclusion criteria: receiving total parenteral nutrition, duration of therapy expected to be $<3$ days, if a \\
cannula was already in situ, terminally ill patients
\end{tabular}


Nishanth 2009 (Continued)

Interventions
Clinically indicated: catheters were removed if the site became painful, the catheter dislodged or there were signs of PVT

Routine replacement: catheters were replaced every $48 \mathrm{~h}$

Outcomes

Primary: incidence of PVT defined as "the development of two or more of the following: pain, erythema, swelling, excessive warmth or a palpable venous cord"

Notes

\section{Risk of bias}

Bias Authors' judgement Support for judgement

Random sequence genera- Unclear risk tion (selection bias)

Evidence: "The patients were allocated to either study or the control group using block randomisation method. The patients were divided into 6 blocks with block sizes of 8 or 10 or 12 arranged randomly".

Comment: how the sequence was generated was not stated. With group sizes of 21 per group, that block sizes make no sense.

Allocation concealment $\quad$ High risk
(selection bias)

Evidence: "Group name was placed (on) an opaque serially numbered sealed envelope (SNOSE)."

Comment: presumably the trial authors meant 'in' an opaque serially numbered sealed envelope - based on subsequent information. The investigator was responsible for allocation.

\begin{tabular}{ll}
\hline $\begin{array}{l}\text { Blinding of participants } \\
\text { and personnel (perfor- }\end{array}$ & Low risk \\
$\begin{array}{l}\text { mance bias) } \\
\text { All outcomes }\end{array}$ & $\begin{array}{l}\text { Comment: neither participants nor clinical personnel were blinded but review } \\
\text { authors do not believe this would introduce bias }\end{array}$
\end{tabular}

\begin{tabular}{|c|c|c|}
\hline $\begin{array}{l}\text { Blinding of outcome as- } \\
\text { sessment (detection bias) } \\
\text { All outcomes }\end{array}$ & High risk & Evidence: "...unblinded study" \\
\hline $\begin{array}{l}\text { Incomplete outcome data } \\
\text { (attrition bias) } \\
\text { All outcomes }\end{array}$ & Low risk & Comment: data for all participants were available \\
\hline $\begin{array}{l}\text { Selective reporting (re- } \\
\text { porting bias) }\end{array}$ & Low risk & Comment: stated outcomes were reported but original protocol not sighted \\
\hline Other bias & High risk & $\begin{array}{l}\text { Extreme results: in this small trial, } 100 \% \text { of participants in the clinically indicat- } \\
\text { ed group developed phlebitis compared with } 9 \% \text { in the } 2 \text {-day change group, } \\
\text { which suggests that chance or other unknown bias affected results. }\end{array}$ \\
\hline
\end{tabular}

Rickard 2010

\begin{tabular}{ll}
\hline Methods & Study design: single-centre RCT \\
& Method of randomisation: computer-generated \\
& Concealment of allocation: telephone service \\
\hline Participants & Country: Australia
\end{tabular}


Number: 362 patients requiring IV therapy in general medical or surgical wards. Clinically indicated: 280 catheters were inserted in 185 participants. Routine replacement: 323 catheters were inserted in 177 participants

Age: clinically indicated 62.7 years (15.5); routine replacement 65.1 years (17.3)

Sex (M/F): clinically indicated 82/103; routine replacement 81/91

Inclusion criteria: > 18 years, expected to have an IVD, requiring IV therapy for $\geq 4$ days

Exclusion criteria: patients who were immunosuppressed, had an existing BSI or those in whom an IVD had been in place for $>48 \mathrm{~h}$

Interventions

Clinically indicated: catheters were removed if there were signs of phlebitis, local infection, bacteraemia, infiltration or blockage

Routine replacement: catheters were replaced every $72-96 \mathrm{~h}$
Primary: phlebitis per person and per 1000 IVD days (defined as $\geq 2$ of the following: pain, erythema, purulence, infiltration, palpable venous cord); IVD-related bacteraemia

Secondary: hours of catheterisation; number of IV devices; device-related BSI; infiltration; local infection

\begin{tabular}{|c|c|c|}
\hline Notes & \multicolumn{2}{|c|}{ Approximately $75 \%$ of participants were receiving a continuous infusion } \\
\hline \multicolumn{3}{|l|}{ Risk of bias } \\
\hline Bias & Authors' judgement & Support for judgement \\
\hline $\begin{array}{l}\text { Random sequence genera- } \\
\text { tion (selection bias) }\end{array}$ & Low risk & Evidence: "Patients were randomly assigned (computer generated)" \\
\hline $\begin{array}{l}\text { Allocation concealment } \\
\text { (selection bias) }\end{array}$ & Low risk & $\begin{array}{l}\text { Evidence: "Assignment was concealed until randomisation by use of a tele- } \\
\text { phone service" }\end{array}$ \\
\hline $\begin{array}{l}\text { Blinding of participants } \\
\text { and personnel (perfor- } \\
\text { mance bias) } \\
\text { All outcomes }\end{array}$ & Low risk & $\begin{array}{l}\text { Evidence: "Open (non-blinded) parallel group RCT" } \\
\text { Comment: neither participants nor clinical personnel were blinded but review } \\
\text { authors do not believe this would introduce bias }\end{array}$ \\
\hline $\begin{array}{l}\text { Blinding of outcome as- } \\
\text { sessment (detection bias) } \\
\text { All outcomes }\end{array}$ & High risk & $\begin{array}{l}\text { Comment: although laboratory staff were blinded for microbiological out- } \\
\text { comes, there were no BSIs; consequently, all other outcome assessment was } \\
\text { at high risk of bias. }\end{array}$ \\
\hline $\begin{array}{l}\text { Incomplete outcome data } \\
\text { (attrition bias) } \\
\text { All outcomes }\end{array}$ & Low risk & Comment: results from all enrolled participants were reported \\
\hline $\begin{array}{l}\text { Selective reporting (re- } \\
\text { porting bias) }\end{array}$ & Low risk & Comment: the protocol was available. All nominated outcomes were reported \\
\hline Other bias & Unclear risk & $\begin{array}{l}\text { Comment: significantly more participants in the routine-change group re- } \\
\text { ceived IV antibiotics }(73.1 \% \text { versus } 62.9 \%)\end{array}$ \\
\hline
\end{tabular}

Methods Study design: multicentre RCT


Method of randomisation: computer-generated, stratified by site

Concealment of allocation: allocation concealed until eligibility criteria was entered into a hand-held computer

Country: Australia
Purticipants
Number: 3283 patients requiring IV therapy in general medical or surgical wards. Clinically indicated:
Age: clinically indicated 55.1 years (18.6); routine replacement 55.0 years $(18.4)$
Sex (M/F): clinically indicated 1022/571; routine replacement $1034 / 656$
Inclusion criteria: patients, or their representative able to provide written consent; $>18$ years, expect-
ed to have an IVD in situ, requiring IV therapy for $\geq 4$ days
Exclusion criteria: patients who were immunosuppressed, had an existing BSI or those in whom an
IVD had been in place for $>48 \mathrm{~h}$ or it was planned for the catheter to be removed $<24 \mathrm{~h}$

Interventions

Clinically indicated: catheters were removed if there were signs of phlebitis, local infection, bacteraemia, infiltration or blockage

Routine replacement: catheters were replaced every $72-96 \mathrm{~h}$

\section{Outcomes}

Primary: phlebitis during catheterisation or within $48 \mathrm{~h}$ of removal (defined as $\geq 2$ of the following: pain, erythema, swelling, purulent discharge, palpable venous cord)

Secondary: CRBSI, all-cause BSI, local venous infection, colonisation of the catheter tip, infusion failure, number of catheters per participant, overall duration of IV therapy, cost, mortality

Notes

\section{Risk of bias}

\begin{tabular}{lll}
\hline Bias & Authors' judgement & Support for judgement \\
\hline $\begin{array}{l}\text { Random sequence genera- } \\
\text { tion (selection bias) }\end{array}$ & Low risk & Evidence: "Random allocations were computer-generated" \\
\hline $\begin{array}{l}\text { Allocation concealment } \\
\text { (selection bias) }\end{array}$ & Low risk & $\begin{array}{l}\text { Evidence: "Random allocations were computer-generated on a hand-held de- } \\
\text { vice, at the point of each patient's entry, and thus were concealed to patients, } \\
\text { clinical staff and research staff until this time" }\end{array}$
\end{tabular}

$\begin{array}{ll}\begin{array}{l}\text { Blinding of participants } \\ \text { and personnel (perfor- }\end{array} & \text { Low risk } \\ \text { es were similarly not masked" }\end{array}$

mance bias)

All outcomes

Comment: neither participants nor clinical personnel were blinded but review authors do not believe this would introduce bias

Blinding of outcome as- High risk sessment (detection bias) All outcomes
Evidence: "... laboratory staff were masked for rating of all microbiological end-points, and a masked, independent medical rater diagnosed catheter-related infections and all bloodstream infections"

Comment: diagnosis of all other outcomes was unblinded

$\begin{aligned} & \text { Incomplete outcome data } \\ & \text { (attrition bias) }\end{aligned}$
Low risk

All outcomes 
Rickard 2012 (Continued)

Selective reporting (re- Low risk The protocol was available and all pre-defined outcomes were reported porting bias)

\begin{tabular}{lll}
\hline Other bias & Low risk & No other known risks of bias \\
\hline
\end{tabular}

Van Donk 2009

\begin{tabular}{ll}
\hline Study design: RCT \\
Method of randomisation: computer-generated \\
Concealment of allocation: sealed envelopes
\end{tabular}

\section{Participants}

Country: Australia

Number: 200. Clinically indicated: 105 participants. Routine replacement: 95 participants

Age: clinically indicated 62.8 years (18.2); routine replacement 54.5 years (19.0)

Sex (M/F): not stated

Inclusion criteria: adult patients who could be treated at home for an acute illness and had a 20-, 22-, or 24-gauge catheter inserted in an upper extremity

Exclusion criteria: not stated

Interventions

Clinically indicated: catheters were removed if there were signs of phlebitis, local infection, bacteraemia, infiltration or blockage

Routine replacement: catheters were replaced every $72-96 \mathrm{~h}$

Outcomes

Primary: phlebitis per participant and per 1000 device days (phlebitis was defined as a total score of $\geq$ 2 points from the following factors: pain (on a 10-point scale, $1=1$ point, and $\geq 2=2$ points; redness $(<1$ $\mathrm{cm}=1$ point, and $\geq 1 \mathrm{~cm}=2$ points); swelling (as for redness); and discharge (haemoserous ooze under dressing $=1$ point, and haemoserous ooze requiring dressing change or purulence $=2$ points)

Also reported on: suspected IVD-related bacteraemia and occlusion/blockage

Notes

\section{Risk of bias}

\begin{tabular}{lll}
\hline Bias & Authors' judgement & Support for judgement \\
\hline $\begin{array}{l}\text { Random sequence genera- } \\
\text { tion (selection bias) }\end{array}$ & Low risk & $\begin{array}{l}\text { Comment: computer-generated allocation (personal communication with tri- } \\
\text { al author) }\end{array}$ \\
\hline $\begin{array}{l}\text { Allocation concealment } \\
\text { (selection bias) }\end{array}$ & Low risk & $\begin{array}{l}\text { Evidence:: "Randomization was concealed until treatment via sealed en- } \\
\text { velopes" }\end{array}$ \\
\hline $\begin{array}{l}\text { Blinding of participants } \\
\text { and personnel (perfor- } \\
\text { mance bias) } \\
\text { All outcomes }\end{array}$ & Low risk & $\begin{array}{l}\text { Comment: neither participants nor clinical personnel were blinded but review } \\
\text { authors do not believe this would introduce bias }\end{array}$ \\
\hline
\end{tabular}

Blinding of outcome as- $\quad$ High risk Outcome assessment unable to be blinded
sessment (detection bias)
All outcomes


Van Donk 2009 (Continued)

Incomplete outcome data Low risk Comment: participant flow chart provided. Results from all enrolled partici(attrition bias) pants were reported

All outcomes

\begin{tabular}{lll}
\hline $\begin{array}{l}\text { Selective reporting (re- } \\
\text { porting bias) }\end{array}$ & Low risk & Comment: all planned outcomes were reported \\
\hline Other bias & Low risk & No other known risks of bias
\end{tabular}

Vendramim 2018

\begin{tabular}{l} 
Study design: multicentre, non-inferiority, RCT \\
Method of randomisation: computer-generated \\
Concealment of allocation: sequentially numbered, sealed envelopes \\
\hline
\end{tabular}

Country: Brazil
Number: 1319 . Clinically indicated: 672 participants. Routine replacement: 647 participants
Age: clinically indicated 59.7 (20.9); routine replacement 59.9 years (20.1)
Sex (M/F): clinically indicated 339/333; routine replacement 318/329
Inclusion criteria:
- "aged at least 18 years, expected use of PIVC for at least 96 hours, patients with PIVC inserted in da-
ta collection units (wards), intensive care units or surgical centres and accepted of the proposals ex-
pressed in the Informed Consent Form by the patient or by someone responsible for the patient. Pa-
tients aged eighteen and older, from two Säo Paulo City hospital" (personal communication)
Exclusion criteria:
- "blood stream infection and or sepsis, neutrophil less than or equal to $1000 / m^{3}$ and simultaneous
use of more than one PIVC" (personal communication)

Interventions

Clinically indicated: catheters were removed according to clinical signs

Routine replacement: catheters were replaced systematically every $96 \mathrm{~h}$

Outcomes Primary: phlebitis

Secondary: pain; infiltration; occlusion; accidental removal; extravasation

\section{Notes}

\section{Risk of bias}

\begin{tabular}{lll}
\hline Bias & Authors' judgement & Support for judgement \\
\hline $\begin{array}{l}\text { Random sequence genera- } \\
\text { tion (selection bias) }\end{array}$ & Low risk & $\begin{array}{l}\text { Evidence: "A computerized randomization program (random.org), a list pre- } \\
\text { pared in blocks of six patients and stratified by ward and per hospital. Thus, } \\
\text { each ward had its own randomization list, totaling 10 lists of randomization, } \\
\text { six in Hospital A and four in Hospital B". (Personal communication) }\end{array}$ \\
\hline $\begin{array}{l}\text { Allocation concealment } \\
\text { (selection bias) }\end{array}$ & Low risk & $\begin{array}{l}\text { Evidence: "At the moment of the recruitment, that is, after the acceptance of } \\
\text { the patient, the assistants have sent a message from a App (whatsApp) and I } \\
\text { indicated the group" }\end{array}$ \\
\hline
\end{tabular}


Vendramim 2018 (Continued)

Comment: the person providing the allocation was unaware of the status of the potential participant and the person recruiting the participant was unaware of the allocation sequence

$\begin{array}{lll}\begin{array}{l}\text { Blinding of participants } \\ \text { and personnel (perfor- }\end{array} & \text { Low risk } & \begin{array}{l}\text { Comment: neither participants nor clinical personnel were blinded but review } \\ \text { authors do not believe this would introduce bias }\end{array}\end{array}$
authors do not believe this would introduce bias mance bias)

All outcomes

\begin{tabular}{lll}
\hline $\begin{array}{l}\text { Blinding of outcome as- } \\
\text { sessment (detection bias) }\end{array}$ & High risk & Unblinded study \\
$\begin{array}{ll}\text { All outcomes } \\
\text { Incomplete outcome data }\end{array}$ & Low risk & No losses in either group. ITT analysis available \\
$\begin{array}{l}\text { (attrition bias) } \\
\text { All outcomes }\end{array}$ &
\end{tabular}

\begin{tabular}{lll}
\hline $\begin{array}{l}\text { Selective reporting (re- } \\
\text { porting bias) }\end{array}$ & Low risk & Expected outcomes reported. Consistent with ClinicalTrials.gov entry \\
\hline Other bias & Low risk & None detected \\
\hline
\end{tabular}

Webster 2007

Study design: single-centre RCT
Methods of randomisation: computer-generated
Concealment of allocation: allocation concealed until telephone contact made with an independent
person

Participants Country: Australia

Number: 206. Clinically indicated: 103 participants. Routine replacement: 103 participants

Age: clinically indicated 60.2 years (16.2); routine replacement 63.1 years (17.3)

Sex (M/F): clinically indicated 53/50; routine replacement 54/49

Inclusion criteria: $\geq 18$ years of age, expected to have an IVD in situ, requiring IV therapy for $\geq 4$ days, catheter inserted by a member of the IV team

Exclusion criteria: immunosuppressed patients and those with an existing BSI

$\begin{array}{ll}\text { Interventions } & \text { Clinically indicated: catheters removed if there were signs of phlebitis, local infection, bacteraemia, } \\ \text { infiltration or blockage }\end{array}$

Routine replacement: catheters replaced every 3 days

Outcomes Primary: composite measure of any reason for an unplanned catheter removal

\section{Secondary: cost:}

- for intermittent infusion: 20 min nursing/medical time, a cannula, a 3-way tap, a basic dressing pack, gloves, a syringe, transparent adhesive dressing, skin disinfection and local anaesthetic per insertion.

- for participants receiving a continuous infusion: all the above costs plus the additional cost of replacing all associated lines, solutions and additives that are discarded when an IV catheter is changed (based on an IV administration set, $1 \mathrm{~L}$ sodium chloride $0.09 \%$ ) 
Webster 2007 (Continued)

Notes

\section{Risk of bias}

\begin{tabular}{|c|c|c|}
\hline Bias & Authors' judgement & Support for judgement \\
\hline $\begin{array}{l}\text { Random sequence genera- } \\
\text { tion (selection bias) }\end{array}$ & Low risk & $\begin{array}{l}\text { Evidence: "Randomization was by computer generated random number list, } \\
\text { stratified by oncology status" }\end{array}$ \\
\hline $\begin{array}{l}\text { Allocation concealment } \\
\text { (selection bias) }\end{array}$ & Low risk & $\begin{array}{l}\text { Evidence: "Allocation was made by phoning a person who was independent of } \\
\text { the recruitment process" }\end{array}$ \\
\hline $\begin{array}{l}\text { Blinding of participants } \\
\text { and personnel (perfor- } \\
\text { mance bias) } \\
\text { All outcomes }\end{array}$ & Low risk & $\begin{array}{l}\text { Evidence: "Clinical staff were subsequently aware of the treatment group" } \\
\text { Comment: neither participants nor clinical personnel were blinded but re- } \\
\text { viewers do not believe this would introduce bias }\end{array}$ \\
\hline $\begin{array}{l}\text { Blinding of outcome as- } \\
\text { sessment (detection bias) } \\
\text { All outcomes }\end{array}$ & High risk & $\begin{array}{l}\text { Evidence: "Research staff had no involvement in nominating the reason for } \\
\text { catheter removal or in diagnosing phlebitis". } \\
\text { Comment: diagnosis of all outcomes were unblinded }\end{array}$ \\
\hline $\begin{array}{l}\text { Incomplete outcome data } \\
\text { (attrition bias) } \\
\text { All outcomes }\end{array}$ & Low risk & Comment: all recruited participants were accounted for in the results \\
\hline $\begin{array}{l}\text { Selective reporting (re- } \\
\text { porting bias) }\end{array}$ & Low risk & Comment: protocol was available. All planned outcomes were reported \\
\hline Other bias & Low risk & No other known risks of bias \\
\hline
\end{tabular}

Webster 2008

\begin{tabular}{ll}
\hline Methods & Study design: single-centre RCT \\
Method of randomisation: computer-generated \\
Concealment of allocation: telephone randomisation \\
\hline Country: Australia \\
Number: 755. Clinically indicated: 379 participants. Routine replacement: 376 participants \\
Age: clinically indicated 60.1 years (17.1); routine replacement 58.8 years (18.8) \\
Sex (M/F): clinically indicated $248 / 131$; routine replacement $233 / 143$ \\
Inclusion criteria: $\geq 18$ years of age, expected to have a IVD in situ, requiring IV therapy for $\geq 4$ days \\
Exclusion criteria: immunosuppressed patients and those with an existing BSI \\
Clinically indicated: catheter removed if there were signs of phlebitis, local infection, bacteraemia, in- \\
filtration or blockage \\
Routine replacement: catheter replaced every 3 days \\
\hline $\begin{array}{l}\text { Primary: a composite measure of phlebitis (defined as } \geq 2 \text { of the following: pain, erythema, purulence, } \\
\text { infiltration, palpable venous cord) and infiltration }\end{array}$ \\
\hline Outcomes
\end{tabular}


Webster 2008 (Continued)

\section{Secondary:}

- infusion-related costs.

* for intermittent infusion: 20-min nursing/medical time, a cannula, a 3-way tap, a basic dressing pack, gloves, a syringe, transparent adhesive dressing, skin disinfection and local anaesthetic per insertion

* for continuous infusion: all the above costs plus the additional cost of replacing all associated lines, solutions and additives that are discarded when an IV catheter is changed (based on an IV administration set, $1 \mathrm{~L}$ sodium chloride $0.09 \%$ )

- Individual reasons for catheter failure (occlusion/blockage, local infection)

Also reported: bacteraemia rate

\section{Notes}

\section{Risk of bias}

\begin{tabular}{|c|c|c|}
\hline Bias & Authors' judgement & Support for judgement \\
\hline $\begin{array}{l}\text { Random sequence genera- } \\
\text { tion (selection bias) }\end{array}$ & Low risk & $\begin{array}{l}\text { Evidence: "Block randomisation was by a computer generated random num- } \\
\text { ber list" }\end{array}$ \\
\hline $\begin{array}{l}\text { Allocation concealment } \\
\text { (selection bias) }\end{array}$ & Low risk & $\begin{array}{l}\text { Evidence: ".... telephoned a contact who was independent of the recruitment } \\
\text { process for allocation consignment" }\end{array}$ \\
\hline $\begin{array}{l}\text { Blinding of participants } \\
\text { and personnel (perfor- } \\
\text { mance bias) } \\
\text { All outcomes }\end{array}$ & Low risk & $\begin{array}{l}\text { Evidence: "Allocation concealment avoided selection bias but clinical staff } \\
\text { were subsequently aware of the treatment group" } \\
\text { Comment: neither participants nor clinical personnel were blinded but review } \\
\text { authors do not believe this would introduce bias }\end{array}$ \\
\hline $\begin{array}{l}\text { Blinding of outcome as- } \\
\text { sessment (detection bias) } \\
\text { All outcomes }\end{array}$ & High risk & $\begin{array}{l}\text { Evidence: "Staff in the microbiological laboratory were blind to group assign- } \\
\text { ment of catheters submitted for testing" } \\
\text { Comment: all other outcomes were unblinded }\end{array}$ \\
\hline $\begin{array}{l}\text { Incomplete outcome data } \\
\text { (attrition bias) } \\
\text { All outcomes }\end{array}$ & Low risk & All recruited participants were accounted for in the results \\
\hline $\begin{array}{l}\text { Selective reporting (re- } \\
\text { porting bias) }\end{array}$ & Low risk & Protocol was available. All planned outcomes were reported \\
\hline Other bias & Low risk & No other known risks of bias \\
\hline
\end{tabular}

Xu 2017

Methods Study design: cluster-RCT of 20 wards in a tertiary referral hospital in China

Method of randomisation: coin toss

Concealment of allocation: coin toss

Participants

Country: China

Number: clinically indicated: 553 patients. Routine replacement: 645 patients.

Age: clinically indicated 58.7 years (39.7); routine replacement 56.2 years (27.1) 
Xu 2017 (Continued)

Sex (M/F): clinically indicated 325/208; routine replacement 335/310

Inclusion criteria: adult patients $>18$ years of age who received catheter infusion; patients who were expected to use the indwelling catheter for $\geq 3$ days; patients who used PIVCs for the first time during hospitalisation; and patients who agreed to participate in this study

Exclusion criteria: patients with BSI or under immunosuppressive therapy; patients receiving parenteral nutrition infusion through PIVC; patients with indwelling catheters for $>72 \mathrm{~h}$ at study entry; and severe infection or hepatocellular failure and renal failure

Interventions

Intervention: PIVCs were removed/replaced if there was a clinical indication to do so

Control: PIVCs were replaced every 3 days in the control group (the routine-replacement group) following hospital policy. The duration of ' 3 days' refers to the approximate $72 \mathrm{~h}$ (range: $48-96 \mathrm{~h}$ ) from the time of insertion to removal of a catheter. They were also removed/replaced if there was a clinical indication to do so

Outcomes Primary: incidence of phlebitis: defined as when $\geq 2$ of the following signs occurred at the catheter ac-
cess site: redness, swelling, fever, pain, or palpable cord-like veins

Secondary: fluid infiltration (when the infused non-blister drug leaked into the surrounding tissue from the normal vascular access, causing tissue swelling around the catheter access site); catheter occlusion (when the drug fluid could not flow into the body or the fluid could not be withdrawn); accidental catheter removal; CRBSI (diagnosed when signs of infection (e.g. fever, chills, and hypotension), positive results, and the same type of bacteria were found in bacterial cultures of both peripheral venous blood and the PIVC tip, and no other apparent source of BSI other than the IV catheter was observed (including BSI within 48 hours of catheter indwelling); local venous infection, i.e. purulent discharge or bloodstream-related infection with no evidence at vein segment; and indwelling time

Notes

\section{Risk of bias}

\begin{tabular}{lll}
\hline Bias & Authors' judgement & Support for judgement \\
\hline $\begin{array}{l}\text { Random sequence genera- } \\
\text { tion (selection bias) }\end{array}$ & Low risk & $\begin{array}{l}\text { Evidence: "These } 20 \text { internal medicine and surgery ward patients were ran- } \\
\text { domly assigned by a research assistant via a coin toss into } 2 \text { groups" }\end{array}$ \\
\hline
\end{tabular}

\begin{tabular}{ll}
\hline $\begin{array}{l}\text { Allocation concealment } \\
\text { (selection bias) }\end{array}$ & Evidence: "These 20 internal medicine and surgery ward patients were ran- \\
domly assigned by a research assistant via a coin toss into 2 groups".
\end{tabular}

Comment: allocation remains concealed until the coin is tossed

$\begin{array}{ll}\begin{array}{l}\text { Blinding of participants } \\ \text { and personnel (perfor- }\end{array} & \text { Low risk } \\ \text { in the groups" }\end{array}$

mance bias)

All outcomes

Evidence for personnel: "Because of the nature of the intervention in this study, the chief nurse in charge of the research wards and the clinical nurses were not blinded to the random grouping"

Comment: neither participants nor clinical personnel were blinded but review authors do not believe this would introduce bias

\begin{tabular}{lll}
\hline $\begin{array}{l}\text { Blinding of outcome as- } \\
\text { sessment (detection bias) }\end{array}$ & High risk & $\begin{array}{l}\text { Evidence: "The peripheral blood samples and the catheter tips of patients } \\
\text { with suspected CRBSI were sent for laboratory examination, and the laborato- } \\
\text { All outcomes }\end{array}$ \\
ry examiners were blinded"
\end{tabular}

Comment: blinding not possible for other outcomes and there was no laboratory confirmed diagnosis 


\section{Xu 2017 (Continued)}

Incomplete outcome data Low risk (attrition bias)

All outcomes
Comment: complete data reporting for all outcomes: after 235 people, who were potentially eligible by belonging to a ward that was randomised, were excluded. 1198 participants were included for the final analysis (flow chart included)

Selective reporting (re- Low risk Comment: expected outcomes reported
porting bias)

Other bias Unclear risk Comment: this was a cluster trial but analysed by individual not cluster

BSI: blood stream infection; CRBSI: catheter-related blood stream infection; ITT: intention-to-treat; IV: intravenous; IVD: peripheral intravenous device; PIVC: peripheral intravenous catheter; PVT: peripheral vein infusion thrombophlebitis; RCT: randomised controlled trial

Characteristics of excluded studies [ordered by study ID]

\begin{tabular}{ll}
\hline Study & Reason for exclusion \\
\hline Arnold 1977 & Not a RCT \\
\hline Cobb 1992 & Involved central, not peripheral lines \\
\hline Eyer 1990 & Involved pulmonary artery or arterial catheters, not peripheral catheters \\
\hline Haddad 2006 & End point was lymphangitis \\
\hline Kerin 1991 & Participants were receiving parenteral nutrition \\
\hline May 1996 & Participants were receiving parenteral nutrition \\
\hline Nakae 2010 & Involved central, not peripheral lines \\
\hline Panadero 2002 & $\begin{array}{l}\text { Compared the use of a single intraoperative and postoperative catheters with } 2 \text { catheters, } 1 \text { used } \\
\text { intraoperatively and a separate catheter for postoperative use }\end{array}$ \\
\hline Rijnders 2004 & Involved central, not peripheral lines \\
\hline
\end{tabular}

RCT: randomised controlled trial

Characteristics of studies awaiting assessment [ordered by study ID]

Chin 2018

\begin{tabular}{ll}
\hline Methods & RCT 1:1 \\
\hline Participants & 113 neonates born at $\geq 32$ weeks' gestation \\
\hline Interventions & PIVC replaced every $72-96$ h or replaced when clinically indicated \\
\hline
\end{tabular}

Outcomes Primary: extravasation

Secondary: phlebitis; leakage; accidental dislodgement

Notes No response to request for additional data as yet


PIVC: peripheral intravenous catheter; RCT: randomised controlled trial

\section{DATA AND ANALYSES}

\section{Comparison 1. Clinically-indicated versus routine change}

\begin{tabular}{|c|c|c|c|c|}
\hline $\begin{array}{l}\text { Outcome or subgroup ti- } \\
\text { tle }\end{array}$ & No. of studies & $\begin{array}{l}\text { No. of partici- } \\
\text { pants }\end{array}$ & Statistical method & Effect size \\
\hline $\begin{array}{l}1 \text { Catheter-related blood } \\
\text { stream infection }\end{array}$ & 7 & 7323 & Risk Ratio (M-H, Fixed, 95\% Cl) & $0.61[0.08,4.68]$ \\
\hline 2 Phlebitis & 7 & 7323 & Risk Ratio (M-H, Fixed, 95\% Cl) & $1.07[0.93,1.25]$ \\
\hline 2.1 Continuous infusion & 6 & 7123 & Risk Ratio (M-H, Fixed, 95\% Cl) & $1.05[0.90,1.23]$ \\
\hline 2.2 Intermittent infusion & 1 & 200 & Risk Ratio (M-H, Fixed, 95\% Cl) & $1.29[0.85,1.96]$ \\
\hline 3 Phlebitis per device days & 6 & 32709 & Risk Ratio (M-H, Fixed, 95\% Cl) & $0.90[0.76,1.08]$ \\
\hline $\begin{array}{l}4 \text { All-cause blood stream } \\
\text { infection }\end{array}$ & 1 & & Risk Ratio (M-H, Fixed, 95\% Cl) & Totals not selected \\
\hline 5 Cost & 3 & 4244 & Mean Difference (IV, Fixed, 95\% Cl) & $-6.96[-9.05,-4.86]$ \\
\hline 6 Infiltration & 6 & 7123 & Risk Ratio (M-H, Fixed, 95\% Cl) & $1.16[1.06,1.26]$ \\
\hline 7 Catheter blockage & 7 & 7323 & Risk Ratio (M-H, Fixed, 95\% Cl) & $1.14[1.02,1.27]$ \\
\hline 8 Local infection & 4 & 4606 & Risk Ratio (M-H, Fixed, 95\% CI) & $4.96[0.24,102.98]$ \\
\hline 9 Mortality & 1 & & Risk Ratio (M-H, Fixed, 95\% Cl) & Totals not selected \\
\hline 10 Pain during infusion & 1 & & Mean Difference (IV, Fixed, 95\% CI) & Totals not selected \\
\hline
\end{tabular}

\section{Analysis 1.1. Comparison 1 Clinically-indicated versus routine change, Outcome 1 Catheter-related blood stream infection.}

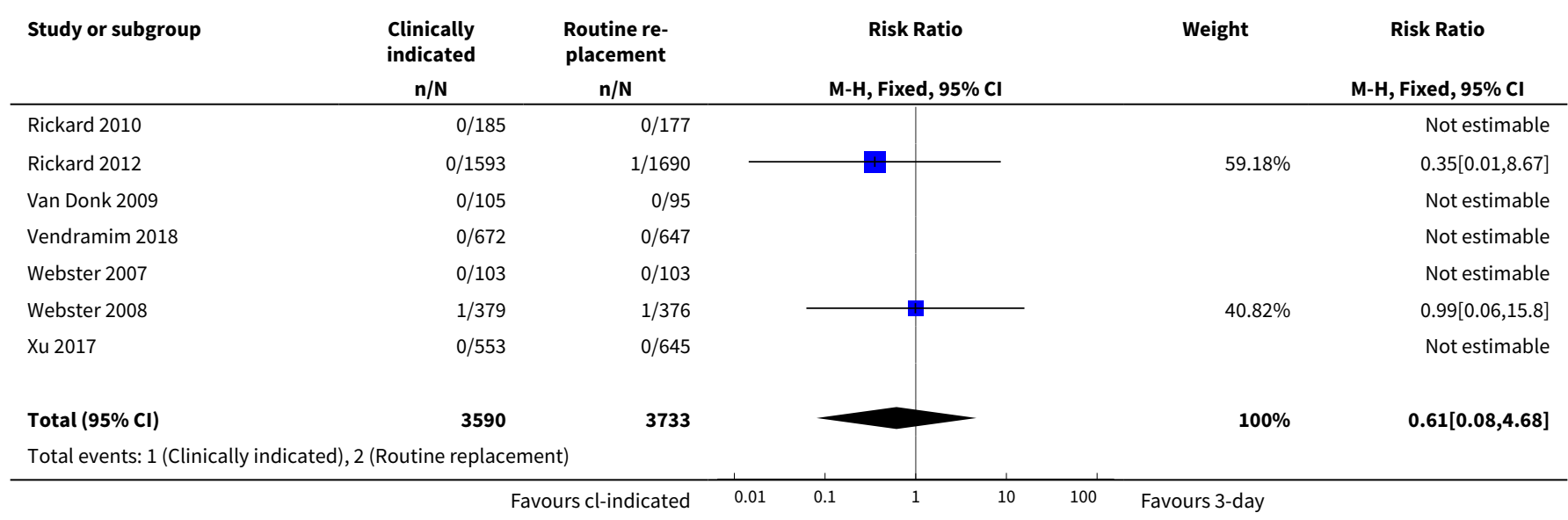




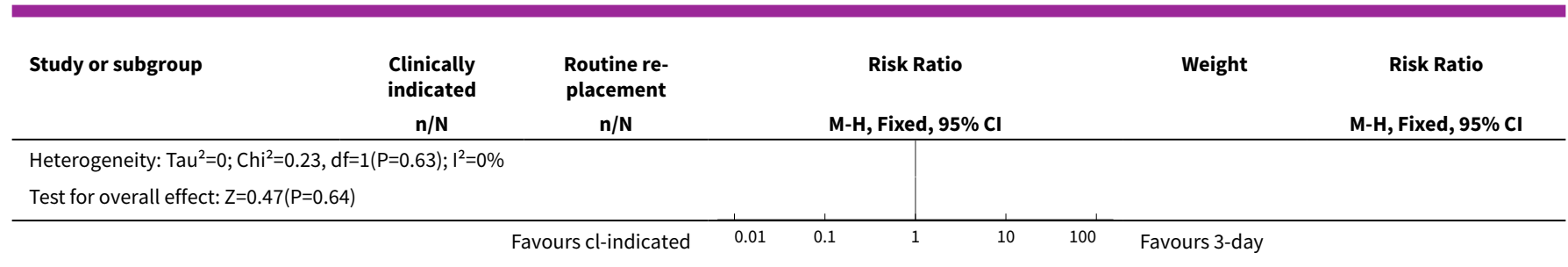

Analysis 1.2. Comparison 1 Clinically-indicated versus routine change, Outcome 2 Phlebitis.

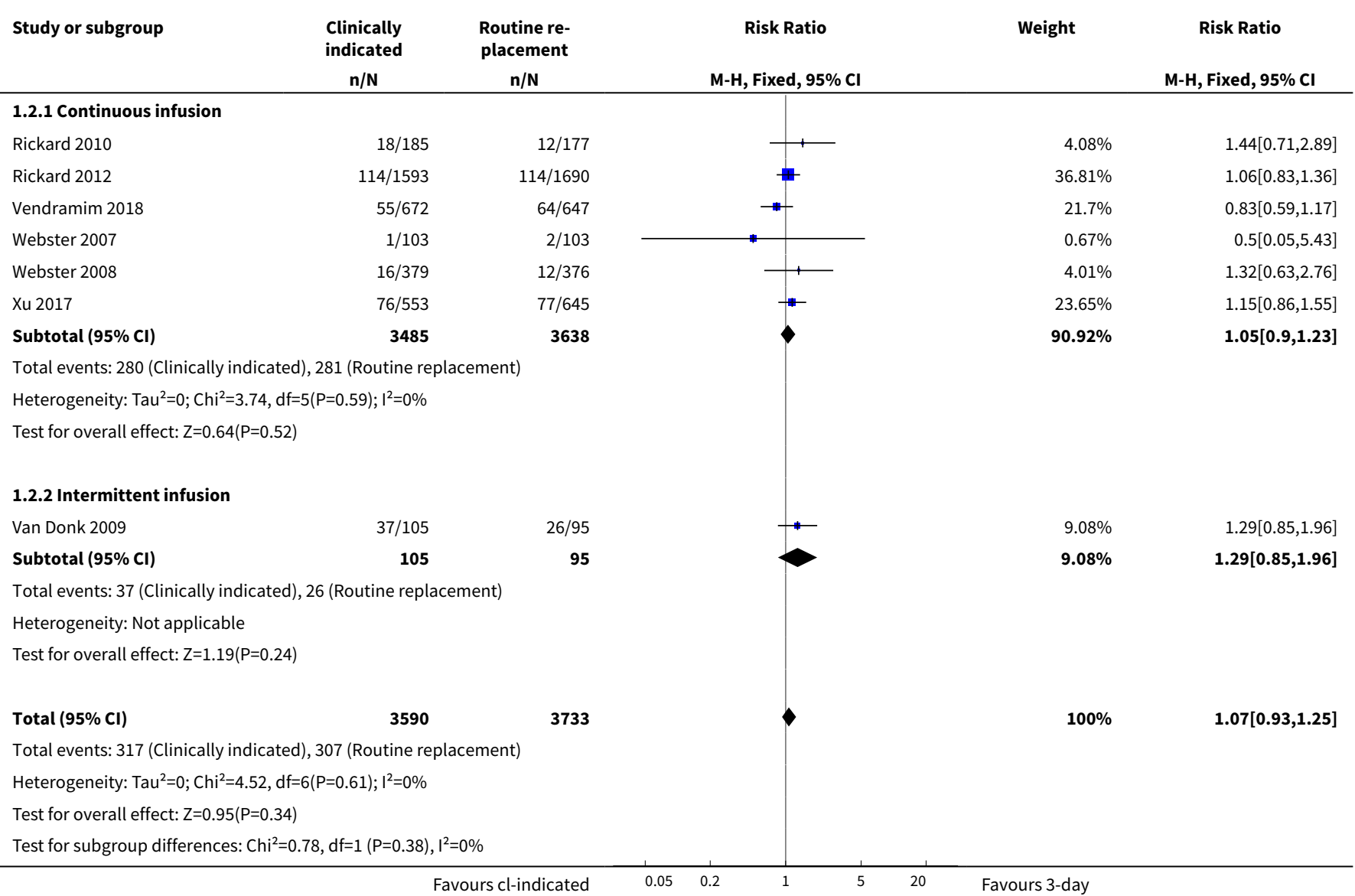

Analysis 1.3. Comparison 1 Clinically-indicated versus routine change, Outcome 3 Phlebitis per device days.

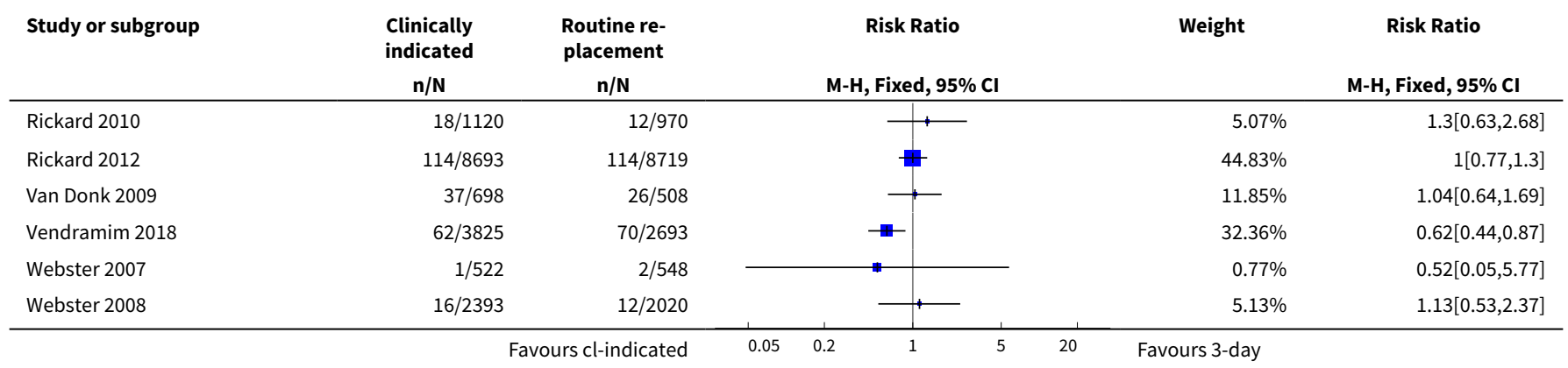




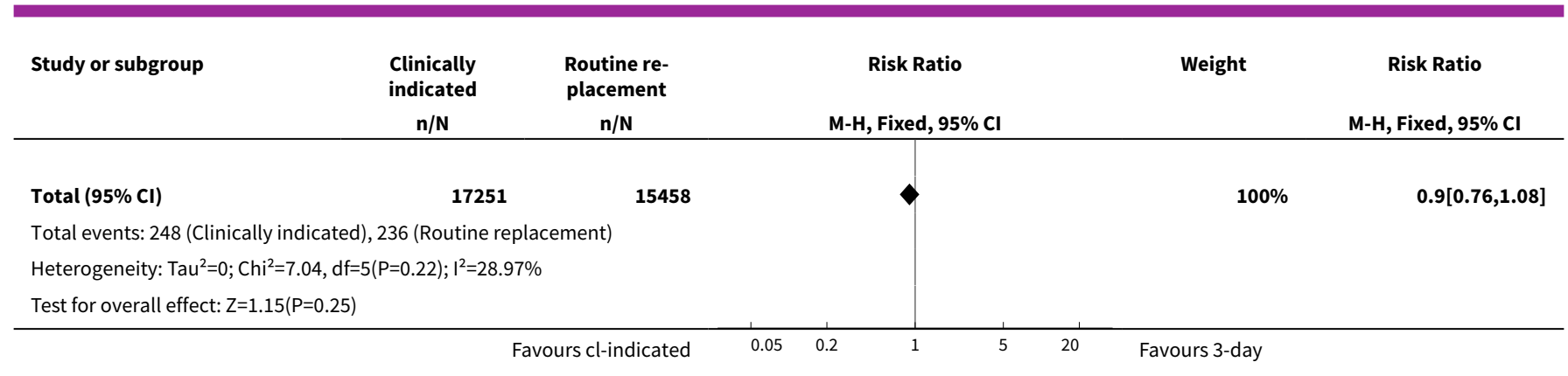

Analysis 1.4. Comparison 1 Clinically-indicated versus routine change, Outcome 4 All-cause blood stream infection.

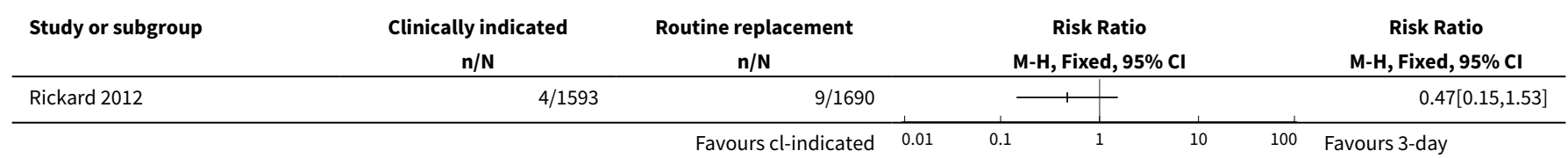

Analysis 1.5. Comparison 1 Clinically-indicated versus routine change, Outcome 5 Cost.

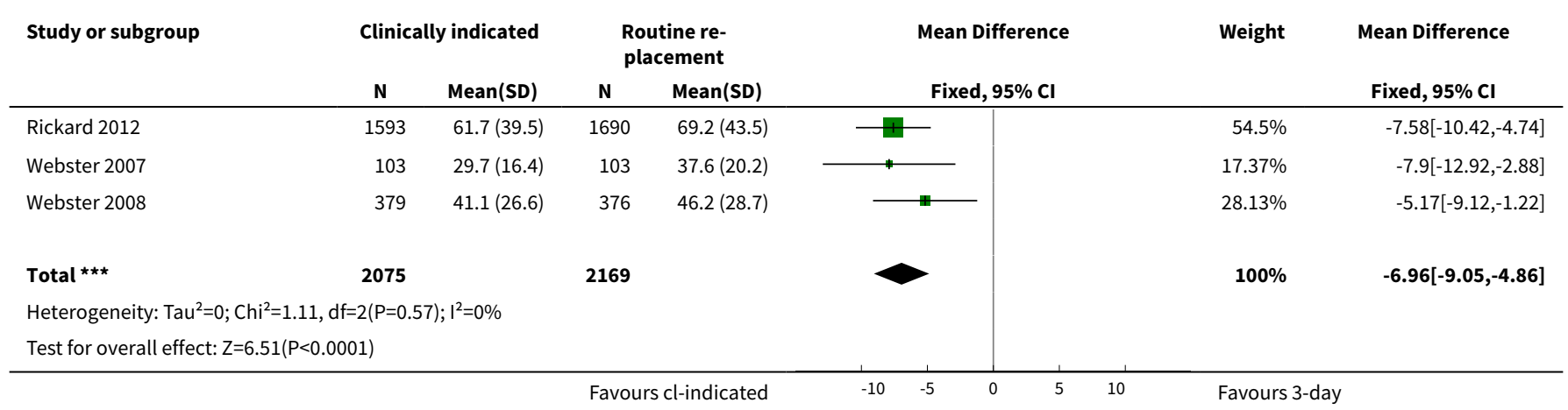

Analysis 1.6. Comparison 1 Clinically-indicated versus routine change, Outcome 6 Infiltration.

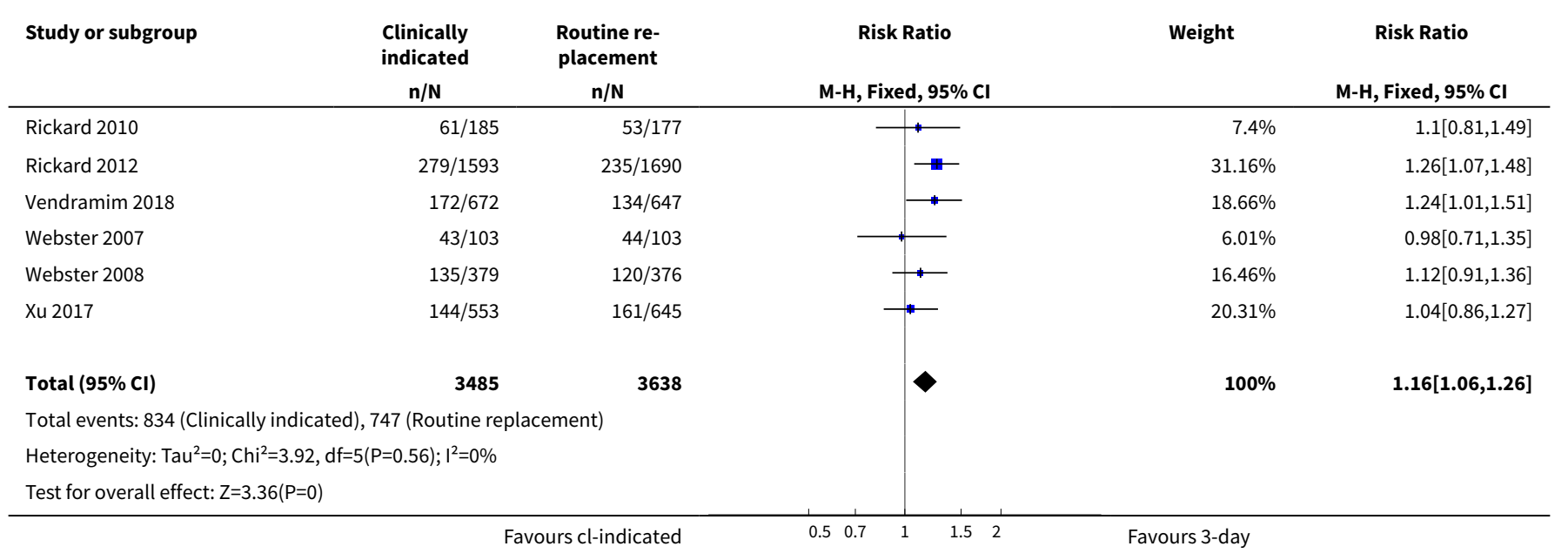


Analysis 1.7. Comparison 1 Clinically-indicated versus routine change, Outcome 7 Catheter blockage.

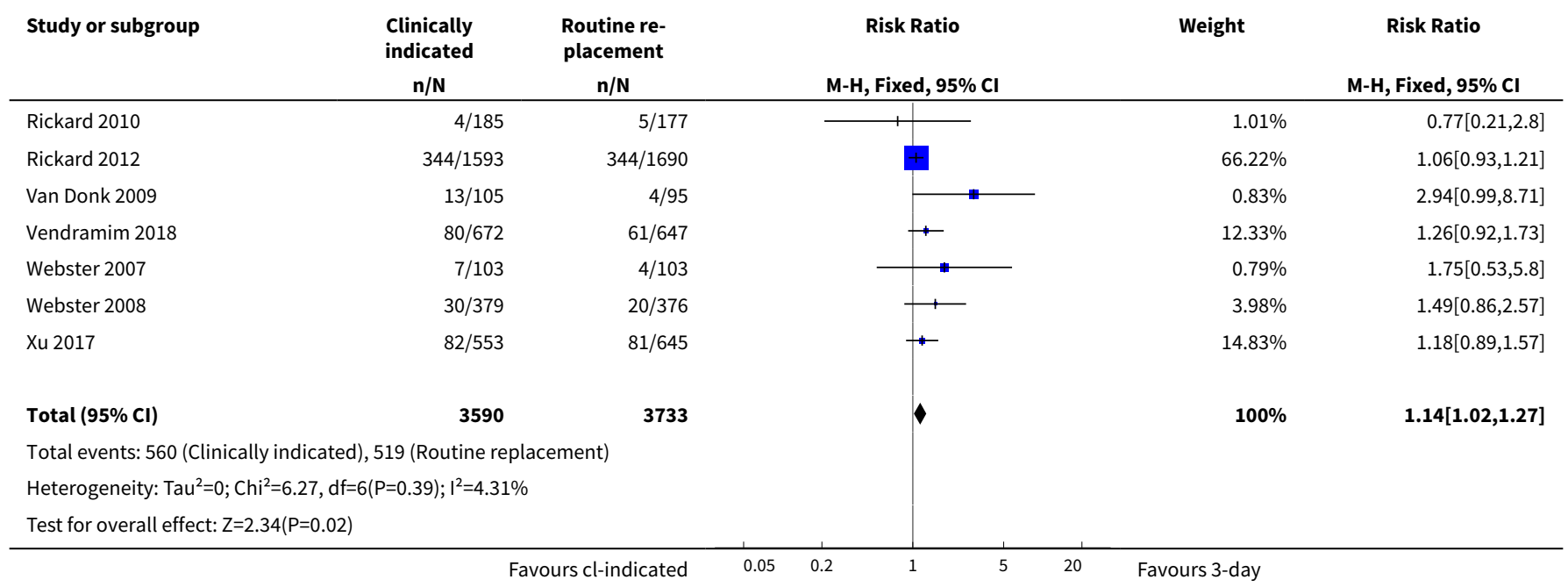

Analysis 1.8. Comparison 1 Clinically-indicated versus routine change, Outcome 8 Local infection.

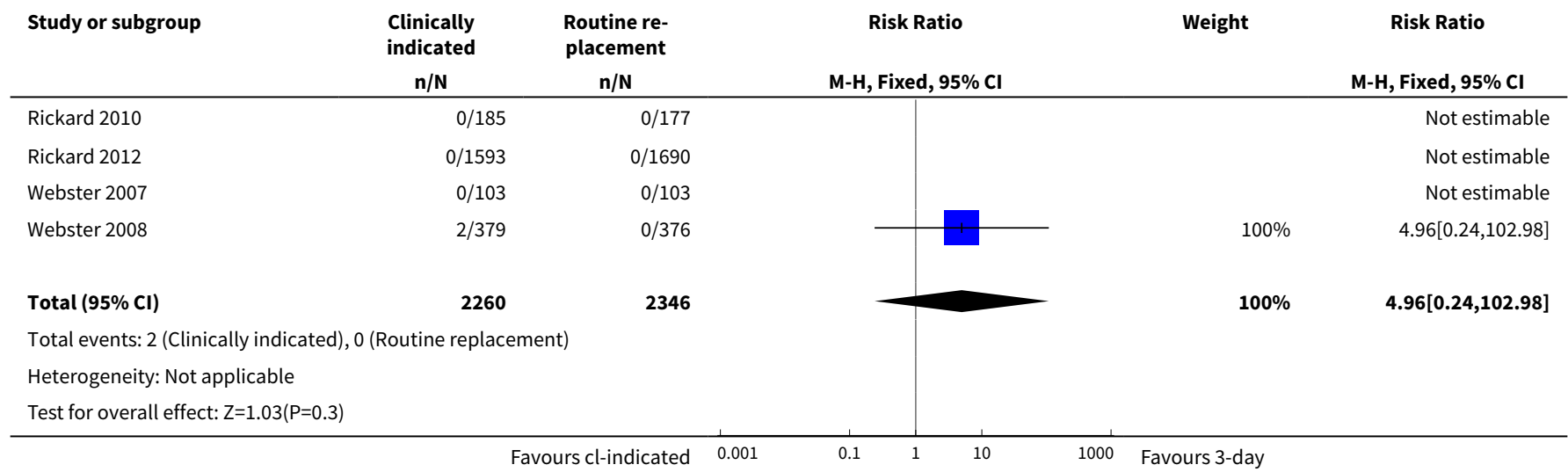

Analysis 1.9. Comparison 1 Clinically-indicated versus routine change, Outcome 9 Mortality.

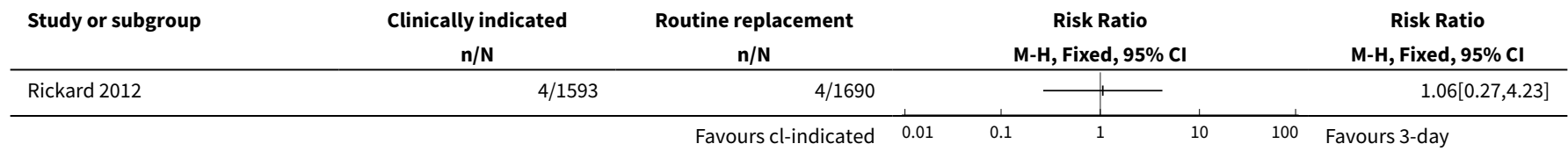


Analysis 1.10. Comparison 1 Clinically-indicated versus routine change, Outcome 10 Pain during infusion.

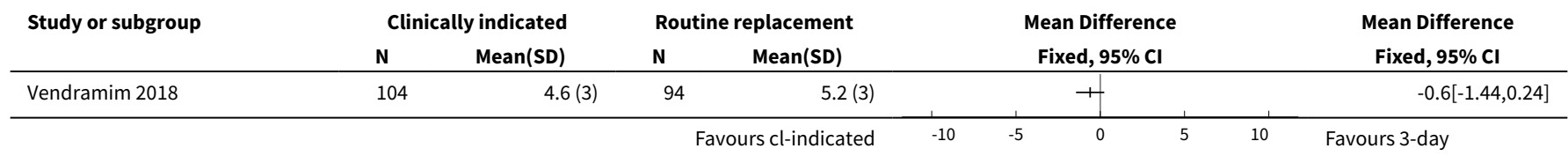

\section{APPENDICES}

\section{Appendix 1. Search strategies}

Cochrane Central Register of Controlled Trials ( 1 January 2015 to 18 April 2018)
\#1 MESH DESCRIPTOR Infusions, Intravenous EXPLODE ALL TREES 9657 1946

\#2 MESH DESCRIPTOR Catheters, Indwelling EXPLODE ALL TREES 933

\#3 MESH DESCRIPTOR Catheterization, Peripheral EXPLODE ALL TREES 804

\#4 catheter*:TI,AB,KY 19185

\#5 cannul*:TI,AB,KY 2736

\#6 (iv near2 (therapy or treatment or device)):TI,AB,KY 817

\#7 (intravenous near2 (therapy or treatment or device)):TI,AB,KY 2643

\#8 \#1 OR \#2 OR \#3 OR \#4 OR \#5 OR \#6 OR \#7 32660

\#9 MESH DESCRIPTOR Device Removal EXPLODE ALL TREES 340

\#10 change:TI,AB,KY 100383

\#11 routine:TI,AB,KY 22763

\#12 (resit* or re-sit* $\left.{ }^{\star}\right): T I, A B, K Y 28$

\#13 replace* :TI,AB,KY 23906

\#14 remov* 18920

\#15 \#9 OR \#10 OR \#11 OR \#12 OR \#13 OR \#14 157711

\#16 \#8 AND \#15 6531

\#17 01/01/2015 TO 17/04/2018:CD 301940

\#18 \#16 AND \#17 1946

catheter $^{\star}$ OR cannul ${ }^{*}$ OR Intravenous Infusions | change OR routine OR replace $^{\star}$ OR remov*

66

US National Institutes of Health Ongoing Trials Register ClinicalTrials.gov (www.clinicaltrials.gov; (1 January 2015 to 18 April 2018))
World Health Organization International Clinical Trials Registry Plat- change OR routine OR replace ${ }^{\star}$ OR remov ${ }^{\star}$ AND catheter ${ }^{\star}$ OR cannul* OR Intra103 venous Infusions 
(Continued)

form ( 1 January 2015 to

18 April 2018)

Medline (Ovid

MEDLINE ${ }^{\circledR}$ Epub Ahead

of Print, In-Process

\& Other Non-In-

MEDLINE ${ }^{\circledR}$ Daily and

Ovid MEDLINE ${ }^{\circledR} 1$ January 2017 to 18 April

2018)
1 exp Infusions, Intravenous/ 52357

725 dexed Citations, Ovid

2 exp Catheters, Indwelling/ 17598

3 exp Catheterization, Peripheral/ 10253

4 catheter ${ }^{\star}$.ti,ab. 183558

5 cannul $^{\star}$. ti,ab. 40302

6 (iv adj2 (therapy or treatment or device)).ti,ab. 5132

7 (intravenous adj2 (therapy or treatment or device)).ti,ab. 16429

81 or 2 or 3 or 4 or 5 or 6 or 7293380

9 exp Device Removal/ 11178

10 change.ti,ab. 920194

11 routine.ti,ab. 255410

12 (resit* $^{\star}$ or re-sit $\left.{ }^{\star}\right) . t i, a b .365$

13 replace ${ }^{\star} . t i, a b .351071$

14 remov $^{\star}$.ti,ab. 559748

15 or/9-14 2002880

168 and 1548953

17 randomized controlled trial.pt. 458816

18 controlled clinical trial.pt. 92332

19 randomized.ab. 409164

20 placebo.ab. 188261

21 drug therapy.fs. 2009753

22 randomly.ab. 288857

23 trial.ab. 425230

24 groups.ab. 1785641

25 or/17-24 4184693

26 exp animals/ not humans.sh. 4446961

2725 not 263616731

2816 and 2712988

$29\left(2017^{\star}\right.$ or $\left.2018^{\star}\right) \cdot$ ed. 1226025

3028 and 29725

Embase 1974 to present

via Ovid ( 1 January

2017 to 18 April 2018)
1 exp intravenous drug administration/ 369547

2866 
4 catheter ${ }^{\star} . t i, a b .271161$

5 cannul $^{\star}$.ti,ab. 54348

6 (iv adj2 (therapy or treatment or device)).ti,ab. 9056

7 (intravenous adj2 (therapy or treatment or device)).ti,ab. 22346

8 or/1-7 771672

9 exp device removal/ 23201

10 change.ti,ab. 1179753

11 routine.ti,ab. 367917

12 (resit $^{\star}$ or re-sit $\left.{ }^{\star}\right)$.ti,ab. 778

13 replace ${ }^{\star}$.ti,ab. 447612

14 remov$^{\star} . t i, a b .704736$

15 or/9-14 2585379

168 and 15101630

17 randomized controlled trial/ 498849

18 controlled clinical trial/ 460351

19 random\$.ti,ab. 1293791

20 randomization/ 77793

21 intermethod comparison/ 233320

22 placebo.ti,ab. 270839

23 (compare or compared or comparison).ti. 465805

24 ((evaluated or evaluate or evaluating or assessed or assess) and (compare or compared or comparing or comparison)).ab. 1727440

25 (open adj label).ti,ab. 63597

26 ((double or single or doubly or singly) adj (blind or blinded or blindly)).ti,ab. 207274

27 double blind procedure/ 148944

28 parallel group $\$ 1 . t i, a b .21584$

29 (crossover or cross over).ti,ab. 92096

30 ((assign $\$$ or match or matched or allocation) adj5 (alternate or group $\$ 1$ or intervention $\$ 1$ or patient $\$ 1$ or subject $\$ 1$ or participant $\$ 1)$ ).ti,ab. 279492

31 (assigned or allocated).ti,ab. 328034

32 (controlled adj7 (study or design or trial)).ti,ab. 291440

33 (volunteer or volunteers).ti,ab. 222779

34 trial.ti. 247887

35 or/17-34 3991617

Clinically-indicated replacement versus routine replacement of peripheral venous catheters (Review) 
(Continued)

3616 and 3523176

$37\left(2017^{\star}\right.$ or $\left.2018^{\star}\right) \cdot$ em. 3311287

3836 and 372866

CINAHL EBSCO (Cumulative Index to Nursing and Allied Health Literature 1 January 2017 to 18 April 2018)
S32 S30 AND S31 163

S31 EM 2018 OR EM 2017 316,890

S30 S16 AND S29 2,084

S29 S17 OR S 18 OR S19 OR S20 OR S21 OR S22 OR S23 OR S24 OR S25 OR S26

OR S 27 OR S28 337,787

S28 (MH "Random Assignment") 37,759

S27 (MH "Single-Blind Studies") or (MH "Double-Blind Studies") or (MH "TripleBlind Studies") 32,600

S26 (MH "Crossover Design") 11,106

S25 (MH "Factorial Design") 914

S24 (MH "Placebos") 8,344

S23 (MH "Clinical Trials") 93,083

S22 TX "multi-centre study" OR "multi-center study" OR "multicentre study" OR "multicenter study" OR "multi-site study" 4,386

S21 TX crossover OR "cross-over" 14,384

S20 AB placebo* 27,965

S19 TX random* 216,193

S18 TX trial $^{\star} 247,155$

S17 TX "latin square" 141

S16 S8 AND S15 9,028

S15 S9 OR S10 OR S11 OR S12 OR S13 OR S14 380,613

S14 TX remov*35,451

S13 TX replace ${ }^{\star} 49,936$

S12 TX (resit* or re-sit $\left.{ }^{\star}\right) 71$

S11 TX routine 39,406

S10 TX change 279,795

S9 (MH "Device Removal+") 2,141

S8 S1 OR S2 OR S3 OR S4 OR S5 OR S6 OR S7 52,305

S7 TX (intravenous n2 (therapy or treatment or device)) 7,224

S6 TX (iv n2 (therapy or treatment or device)) 1,512

S5 TX cannul* 3,489

S4 TX catheter* 38,647 
S3 (MH "Catheterization, Peripheral+") 2,413

S2 (MH "Catheters+") 8,493

S1 (MH "Infusions, Intravenous") 5,632
AMED Ovid (Allied and Complementary Medicine 1 January 2017 to 18 April 2018)
1 exp catheterization/ 179
3 cannul*.ti,ab. 138

4 (iv adj2 (therapy or treatment or device)).ti,ab. 45

5 (intravenous adj2 (therapy or treatment or device)).ti,ab. 89

61 or 2 or 3 or 4 or 5732

7 "Device Removal".ti,ab. 1

8 change.ti,ab. 10950

9 routine.ti,ab. 1844

10 (resit* $^{\star}$ or re-sit $\left.{ }^{\star}\right)$ ti,ab. 5

11 replace ${ }^{\star}$.ti,ab. 2253

12 remov $^{\star} . t i, a b .2128$

13 or/7-12 16623

146 and 13106

15 exp CLINICAL TRIALS/ 3720

16 RANDOM ALLOCATION/ 314

17 DOUBLE BLIND METHOD/ 650

18 Clinical trial.pt. 1210

19 (clinic $^{\star}$ adj trial*).tw. 5347

20 ((singl ${ }^{\star}$ or doubl ${ }^{\star}$ or trebl ${ }^{\star}$ or tripl $\left.{ }^{\star}\right)$ adj (blind ${ }^{\star}$ or mask $\left.\left.{ }^{\star}\right)\right)$. tw. 2804

21 PLACEBOS/ 583

22 placebo*.tw. 3084

23 random*.tw. 17338

24 PROSPECTIVE STUDIES/ 1065

25 or/15-24 22298

2614 and 2523

27 ("2017" or "2018").yr. 699

2826 and 271

\section{WHAT'S NEW}




\begin{tabular}{lll}
\hline Date & Event & Description \\
\hline 23 August 2018 & $\begin{array}{l}\text { New citation required but conclusions } \\
\text { have not changed }\end{array}$ & $\begin{array}{l}\text { Searches re-run. Two new studies included. No new studies } \\
\text { excluded. One study awaiting classification. Text updated. No } \\
\text { change to conclusions. }\end{array}$ \\
\hline 23 August 2018 & New search has been performed & $\begin{array}{l}\text { Searches re-run. Two new studies included. No new studies ex- } \\
\text { cluded. One study awaiting classification. }\end{array}$ \\
\hline
\end{tabular}

\section{HISTORY}

Protocol first published: Issue 2, 2009

Review first published: Issue 3, 2010

\begin{tabular}{lll}
\hline Date & Event & Description \\
\hline 25 March 2015 & $\begin{array}{l}\text { New citation required but conclusions } \\
\text { have not changed }\end{array}$ & $\begin{array}{l}\text { Searches re-run. No additional studies included or excluded. Mi- } \\
\text { nor changes to the text to adhere to current Cochrane standards. }\end{array}$ \\
\hline 25 March 2015 & New search has been performed & Searches re-run. No additional studies included or excluded. \\
\hline
\end{tabular}

\section{CONTRIBUTIONS OF AUTHORS}

JW: conceived the idea for the review, wrote the protocol, selected trials for inclusion, assessed methodological quality of trials and extracted data, entered the data, developed the analysis plan for the update and drafted the review update, guarantor of the review. SO: wrote the protocol, arbitrated on the selection of trials, assisted with data extraction, assessed methodological quality and assisted in drafting the final review.

CR: critically reviewed the protocol before final submission, selected trials for inclusion, assessed methodological quality of trials, extracted data, assisted with interpreting results and drafting of the final review.

NM: selected trials for inclusion, assessed methodological quality of trials, extracted data, and commented on the review update.

\section{DECLARATIONSOF INTEREST}

JW: none known

SO: none known

CR: CR's employer has received unrestricted research grants in aid from manufacturers of peripheral intravenous catheters and products, on her behalf for academic research projects. CR's employer has also received competitively awarded research grants through professional bodies where the funds came from commercial suppliers. These sponsors (3M, Adhezion, Angiodynamics, BD-Bard, Baxter, Medtronic, Centurion Medical, Entrotech Life Sciences, Cook, Smiths Medical) had no involvement in the study design, execution, analysis or publication of these projects, had no control over the projects, and they were unrelated to the topic of this review. CR is an academic researcher and her employer has received funding on her behalf for her to provide consultancies (expert advice, advisory panel participation, and educational lectures about her research at professional symposia and other events) from ResQDevices, Smiths Medical and BD-Bard.

NM: NM's employer has received unrestricted grants in aid from manufacturers of peripheral intravenous catheters and products, on her behalf for academic research projects. These sponsors (3M, Adhezion, BD, Centurion Medical Products, Cook Medical, Entrotech, Teleflex) had no involvement in the study design, execution, analysis or publication of these projects and they were unrelated to the topic of this review. NM is an academic researcher and her employer has received funding on her behalf for her to provide expert advice, or educational lectures on her research at professional symposia and other events from BD and Hospira.

Some of the review authors were also the investigators on several of the included trials, To eliminate any potential for a conflict of interest, assessment was allocated to a review author who was not an investigator.

\section{SOURCES OF SUPPORT}

\section{Internal sources}

- No sources of support supplied 


\section{External sources}

- Chief Scientist Office, Scottish Government Health Directorates, The Scottish Government, UK.

The Cochrane Vascular editorial base is supported by the Chief Scientist Office.

\section{DIFFERENCES BETWEEN PROTOCOLANDREVIEW}

\section{8 update}

- We added funding source; ethics approval and consent; and prospective registration on a clinical trials register; to our data extraction tool

- We also added the following outcome to the 'Summary of Findings' table:

* all-cause blood stream infection

\section{Previous updates}

We changed the primary outcome to catheter-related bloodstream infection; and added all-cause bloodstream infection as a separate primary outcome. This was to more closely differentiate between the two outcomes. The methodological quality assessment of the included studies was updated to the Cochrane Collaboration tool for assessing risk of bias (Higgins 2017).

\section{INDEX TERMS}

\section{Medical Subject Headings (MeSH)}

Catheter-Related Infections [ ${ }^{*}$ prevention \& control]; Catheterization, Peripheral [adverse effects] [economics] [*instrumentation]; Catheters, Indwelling [adverse effects]; Device Removal [*standards]; Guideline Adherence; Incidence; Phlebitis [epidemiology] [etiology]; Randomized Controlled Trials as Topic; Thrombophlebitis [epidemiology] [etiology]; Time Factors

\section{MeSH check words}

Humans 